\title{
Phyto-polyphenols as potential inhibitors of breast cancer metastasis
}

\author{
Dimiter Avtanski ${ }^{1,2^{*}}$ and Leonid Poretsky ${ }^{1}$
}

\begin{abstract}
Breast cancer is the most common cancer among women as metastasis is currently the main cause of mortality. Breast cancer cells undergoing metastasis acquire resistance to death signals and increase of cellular motility and invasiveness.

Plants are rich in polyphenolic compounds, many of them with known medicinal effects. Various phyto-polyphenols have also been demonstrated to suppress cancer growth. Their mechanism of action is usually pleiotropic as they target multiple signaling pathways regulating key cellular processes such as proliferation, apoptosis and differentiation. Importantly, some phyto- polyphenols show low level of toxicity to untransformed cells, but selective suppressing effects on cancer cells proliferation and differentiation.

In this review, we summarize the current information about the mechanism of action of some phyto-polyphenols that have demonstrated anti-carcinogenic activities in vitro and in vivo. Gained knowledge of how these natural polyphenolic compounds work can give us a clue for the development of novel anti-metastatic agents.
\end{abstract}

Keywords: Polyphenols, Breast cancer, Metastasis, Plant products, Resveratrol, EGCG, Kaempferol

\section{Background}

Breast cancer is the most common cancer in women, accounting for nearly 1 in 3 diagnosed cancers or $16 \%$ of all female cancers. The incidence of breast cancer increases with age and is expected to escalate due to the increase in life expectancy and the adoption of the Western lifestyle and rising rates of obesity. In spite of the advances in treatment, metastasis remain the main cause of mortality in cancer patients contributing to $90 \%$ of deaths from solid tumors (Gupta \& Massagué 2006).

Natural products are used in traditional medicine over the millennia for prevention and treatment of variety of maladies, including cancer. Plants are rich in polyphenolic compounds and many of these compounds have proven beneficial effects in preventing the initiation and development of metastasis. Natural polyphenols have generally pleiotropic effects in the cell, activating multiple signaling pathways thus affecting many aspects of cellular fate, including cell apoptosis, proliferation, and differentiation. In

\footnotetext{
* Correspondence: davtanski@northwell.edu

${ }^{1}$ Gerald J. Friedman Diabetes Institute at Lenox Hill Hospital, Northwell Health, New York, NY 10022, USA

${ }^{2}$ Division of Endocrinology and Metabolism, Department of Medicine, Friedman Diabetes Institute at Lenox Hill Hospital, Northwell Health, $110 \mathrm{E}$ 59th Street, Suite 8B, Room 837, New York, NY 10022, USA
}

this regard, it is worth studying the mechanism of action of the natural polyphenols which can give us clues for the development of new synthetic therapeutic molecules.

In this review, we summarize the main in vitro and in vivo effects of some promising phyto-polyphenols that have shown suppressing actions in the initiation and progression of metastasis in breast cancer. Some of these polyphenolic compounds are already in phase I, II, or III clinical trials.

\section{Breast cancer and metastasis Epidemiology of breast cancer and metastasis} According to the American Cancer Society, the average age at the time of breast cancer diagnosis is 61 years. Although, breast cancer predominates in women, about of $1 \%$ of all cases occur in men. Among the different ethnicities, breast cancer incidence rates are higher in non-Hispanic Caucasian women compared to African American women, but mortality rates are higher among African Americans (32\%) compared to non-Hispanic Caucasians (24\%). The most recent data for American women diagnosed with breast cancer demonstrate survival rates of 89,82 , and $77 \%$ at 5,10 , and 15 years after diagnosis (American Cancer Society, 2011). 
Human breast cancer is a heterogenous disease, which can be classified into different groups depending on the presence or absence of estrogen receptor (ER), progesterone receptor (PR), and human epidermal growth factor receptor 2 (HER2) expression. The expression of these three receptors strongly defines breast cancer behavior and treatment options. For example, HER2-positive breast cancers are more aggressive in nature, but respond better to the current therapy resulting in more favorable prognosis. Much more challenging are the triple-negative breast cancers (TNBC) (ER/PR/HER2-negative), constituting between 10 and $20 \%$ of all breast cancers, which are characterized by most aggressive behavior and lack effective therapies.

The prognosis in breast cancer strongly depends on the presence or absence of metastasis in other organs. Today, around 155,000 people in the United States live with metastatic breast cancer and approximately $6-10 \%$ of all newly diagnosed breast cancer patients are present with metastatic disease at the time of diagnosis (American Cancer Society, 2011) (NCI SEER 2018). Cancer metastases occur in $20-30 \%$ of all breast cancer cases and the median survival of metastatic breast cancer patients is on average 3 years (O’Shaughnessy 2005).

\section{Mechanism of breast cancer metastasis}

Metastasis is a process involving interplay between the cancer cells with their biological properties and the host distant site providing specific microenvironment. Particular tumors have the affinity to spread in particular organs. In 1889 Stephen Paget formulated the so called "seed and soil" theory, which is based on autopsy records of 735 women with breast cancer (Paget 1989). According to this theory, the 'seed' is the metastatic cell, and the 'soil' the metastatic site. The basic idea behind the Paget's theory is that in order to metastasize, cancer cell must find a suitable location bearing certain characteristics. Later, in 1928, the American pathologist James Ewing challenged the "seed and soil" theory, suggesting that the organ specific metastases could be explained by pure anatomical and mechanical circulatory patterns between the primary tumor and the distant organs (Ewing 1928). In fact, the compatibility between the cancer cells and the host environment as well as the circulatory patterns play roles in the metastatic process. The determination which organ would be a target for cancer invasion depends on the proximity of the tumor side to the host organ and the connection between the primary tumor and the metastatic site through the vascular circulatory system. For example, breast cancer commonly metastasizes to bones or the ovaries. In addition to using blood vessels, cancer cells (e.g. breast carcinoma cells) can migrate by invading the lymph nodes and using the lymphatic system, but they ultimately rely on the blood vessels to find their way to the distant site.

To be able to metastasize the cancer cell must undergo physiological changes and overcome numerous obstacles. Generally, the metastatic process could be divided into several defined stages: (1) loss of cellular adhesion, (2) increase of cellular motility and invasiveness, (3) entry and survival in the circulation, (4) spread into distant tissue, and (5) colonization of the distant site (Chambers et al. 2002). At the beginning of the metastatic process, the primary tumor needs to develop its own blood circulatory system which also provides a route for tumor migration. Progression toward metastasis requires acquiring a resistance to cell death signals accomplished by overexpression of anti-apoptotic effector genes such as B-cell lymphoma 2 (BCL2), BCL-XL, and X-linked inhibitor of apoptosis protein (XIAP) (Mehlen \& Puisieux 2006). Cancer cells undergoing metastasis are characterized by increased expression of matrix metalloproteinases (MMPs), which proteolytically disrupt the protective basal membrane (MacDougall \& Matrisian 1995). Secreted proteases generate a variety of bioactive cleavage peptides which further modulate cancer cell migration, proliferation, survival, and tumor angiogenesis (Gupta \& Massagué 2006). Once the cancer cells enter the bloodstream, they increase the secretion of proteins such as autocrine motility factor (AMF) and motility-stimulating protein (MSP) which enable them to survive the harsh conditions in the bloodstream (Watanabe et al. 1991). Finally, the cancer cells extravasate from the circulation and enter the new site where they form pre-angiogenic micrometastases (Chambers et al. 2002).

Underlying event in metastasis is the epithelial-tomesenchymal transition (EMT), a process in which particular cells lose their epithelial characteristics and gain more mesenchymal-like features. During EMT the cellular expression of cell adhesion molecules (CAMs) decrease resulting in the formation of spindle-shape morphology. EMT is a fundamental process occurring during the embryonal development (designated as Type I EMT), fibrosis or wound healing (or Type II EMT), but EMT also plays a key role in cancer metastasis (also known as Type III EMT) (Kalluri \& Weinberg 2009). Main event during EMT is the cleavage of the tight junction cell surface protein E-cadherin and inhibition of its expression by SNAIL, SLUG, ZEB and TWIST transcription factors accompanied by overexpression of $\mathrm{N}$-cadherin, fibronectin, vimentin and other proteins (Peinado et al. 2007; Yang \& Weinberg 2008). Cancer cells involved in EMT undergo dynamic cytoskeletal rearrangements interacting intensively with the cell-matrix. This process is governed by growth factors, which directly or indirectly modulate plasma membrane 
proteases and focal adhesion disassembly (Gupta \& Massagué 2006).

Migratory cancer cells show elevated expression MMPs, which are Calcium-dependent Zinc-containing endopeptidases capable of degrading extracellular matrix (ECM) proteins (Verma \& Hansch 2007). There is a strong correlation between the MMP expression and cancer invasion and metastasis (Kanadaswami et al. 2005). MMPs participate in all stages of carcinogenesis and are particularly important for tumor invasion (McCawley \& Matrisian 2000). Generally, overexpression of MMPs is linked to higher metastasis capacity in many tumors (Kanayama 2001; Saito et al. 2007; Castellano et al. 2008; Lee et al. 2008). Expression of MMPs is induced by growth factors (like epithelial growth factors [EGFs]) and receptor tyrosine kinase (RTKs) (such as EGF receptor [EGFR]) involving PI3K (phosphatidylinositol-3-kinase) and NF- $\mathrm{KB}$ (nuclear factor kappa-light-chain-enhancer of activated B cells) signaling cascades (Sen \& Chatterjee 2011). Experimental results have shown that inhibition of MMPs results in abolishment of tumor cell invasiveness (Matrisian 1990; Rhee \& Coussens 2002; Van den Steen et al. 2002; Kanadaswami et al. 2005). For this reason, MMPs are considered as important molecular targets for the anticancer therapy. Among the 23 currently known human MMPs, the gelatinases (also known as type IV collagenases) MMP-2 ( $s$. gelatinase A) and MMP-9 ( $s$. gelatinase B) play key roles in the metastatic process. MMP-2 and -9 are suppressed by tissue inhibitors of metalloproteinases (TIMPs) (Visse \& Nagase 2003). There are four different TIMPs, TIMP1, 2, 3, and 4, which bind non-covalently to MMP thus inhibiting their expression (Brew \& Nagase 2010).

$\mathrm{NF}-\mathrm{KB}$ is a main player in the metastatic process because it is crucial regulator of cell proliferation and survival. NF- $\mathrm{kB}$ levels may predict the potential of the tumor cells to metastasize (Jin et al. 2014). In resting cells NF- $\mathrm{kB}$ exists in inactive form, located in the cytoplasm, bound to a family of inhibitory proteins referred as I $\kappa B$ (inhibitors of $\kappa B$ ). Members of I $\mathrm{K} B$ family include ІкB- $\alpha$, ІкB- $\beta$, ІкB- $\gamma$, ІкB- $\varepsilon$, ІкB- $\zeta, p 105, p 100$, and bcl3, as IкB- $\alpha$ (also known as nuclear factor of kappa light polypeptide gene enhancer in B-cells inhibitor-alpha [NFKBIA]) is the most abundant among them. The control of NF- $\kappa B$ activity is carried out by IкB kinase (IKK) kinases which include mitogen-activated protein kinase kinase (MAPKK) family comprising of NF-kB-inducing kinase (NIK) and MAPK/ERK kinase kinase (MEKK) 1 , 2 , and 3 . When activated, NF- $\mathrm{kB}$ translocates to the nucleus where it serves as transcription factor regulating genes controlling cell cycle, apoptosis, transformation, and other processes. Constitutively active NF- $\mathrm{kB}$ is characteristic for many cancers. It protects the activation of apoptotic signal by inhibiting p53 activity thus promoting the survival and neoplastic transformation of the cancer cells. The NF- $\mathrm{kB}$ signaling induces the expression of a number of target genes involved in angio- and lymphangiogenesis among them the vascular endothelial growth factor (VEGF). NF- $\mathrm{kB}$ directly induces the expression of urokinase-type plasminogen activator (uPA) (Sliva et al. 2002), MMP-9, and chemokine receptor CXCR4 (Helbig et al. 2003), which in turn results in promotion of ECM degradation and metastasis. The regulation of tumor metastasis by NF- $\mathrm{KB}$ is exerted by reciprocal regulation of prometastatic (heparanase, etc.) and antimetastatic (MMP-1, MMP-2, plasminogen activator inhibitor [PAI]-2, etc.) factors. Thus NF- $\mathrm{kB}$ is considered as an attractive candidate for metastasis treatment. Number of developed therapeutic agents aim to target NF- $\kappa B$ activity and function by different approaches such as induction of $\mathrm{I} \kappa \mathrm{B} \alpha$ expression or prevention of its degradation, inhibition of NF- $\mathrm{kB}$ nuclear translocation, suppression of NF- $\kappa B$ binding to DNA, inhibition of IKK functions, etc. (Wu \& Kral 2005)

It is widely accepted that tumors are initiated by small proportion of cancer stem cells (CSCs) that possess capacity for indefinite self-renewal. CSCs bear $\mathrm{CD}_{4} 4^{+} /$ $\mathrm{CD} 24^{-/ \text {low }}$ lineage characteristics and differentiate into all other cellular phenotypes in the solid tumor as well as they can initiate the formation of secondary tumors. Recent experimental results suggest that microRNAs (miRs) play a critical role in the formation of CSCs and the acquisition of EMT (Li et al. 2010).

\section{Role of tumor microenvironment in breast cancer metastasis}

Tumor is a complex structure comprised not only by the neoplastic cells, but also by other cellular types of a different origin, all of them residing in a specific ECM microenvironment and communicating via soluble substances (Yu \& Di 2017). Tumor-infiltrating lymphocytes (TILs) are component of the tumor microenvironment that play a major role in cancer development. Most of the TILs are $\mathrm{CD}^{+}{ }^{+} \mathrm{T}$ cells, $\mathrm{CD} 4^{+}$helper $\mathrm{T}$ cells (Th), and $\mathrm{CD}^{+}$regulatory $\mathrm{T}$ cells (Tregs), as evidence suggest that TILs are predictor of tumor outcome (Haanen et al. 2006). Huang et al. (2015) demonstrated that although both, $\mathrm{CD} 8^{+}$and $\mathrm{CD} 4^{+}$cells have a role in cancer, during breast cancer development the number of Th cells increase concomitantly with a change of their dominant subsets from Th1 to Treg. On the other hand, $\mathrm{CD}^{+}$ cells are inverse indicator of ER and PR status in the breast tumor and may predict the clinical outcome (Mahmoud et al. 2011). Another component of the tumor microenvironment are the tumor-associated macrophages (TAMs) which are monocytes recruited by cytokines (such as the chemokine ( $\mathrm{C}-\mathrm{C}$ motif) ligand 2 [CCL2]) from the peritumoral tissues or bone marrow. TAMs can be divided into M1 and M2 machrophages, but 
studies also suggest that they may actually possess characteristics of both (Yu \& Di 2017). Driven by interleukin (IL)-4 and IL-10, tumor necrosis factor-alpha (TNF $\alpha$ ), macrophage colony-stimulating factor (M-CSF), or hypoxia, breast tumor microenvironment facilitate M1 differentiation into M2 (Laoui et al. 2011). Hypoxia of the white adipose tissue may be induced by obesity and can further lead to endocrine alterations promoting the secretion of proinflammatory and angiogenic cytokines, and downregulating CCAAT-enhancer binding protein-alpha (C/EBP $)$ thus inhibiting apoptosis and stimulating cell proliferation (Ye et al. 2007; Khan et al. 2013). Since the cytokines released by the M1 macrophages in the early stages of cancer development have anti-proliferative effects on tumor cells, the increased proportion of M2 macrophages in the later stage of tumor development facilitate cancer growth (Quail \& Joyce 2013). Cancer-associated fibroblasts (CAFs) are other component of the tumor microenvironment. It is suggested that these cells have heterogeneous origin and derive from neighboring tissue fibroblasts, bone marrow mesenchymal cells, epithelial cells undergoing EMT or other cellular types (Shiga et al. 2015). CAFs directly modulate tumor progression and metastasis by secreting growth factors and cytokines that promote ECM remodeling, cellular proliferation, EMT, and angiogenesis (Cirri \& Chiarugi 2011). Adipocytes are main component of the mammary gland. In human, fat volume comprises an average of $25 \%$ (7-56\%) (Vandeweyer \& Hertens 2002) of the non-lactating and an average of $35 \%(9-54 \%)$ (Ramsay et al. 2005) of the lactating breast tissue. Mammary adipose cells share characteristics with the subcutaneous WAT adipocytes, but are distinctive from these cells by their response to menstrual cycle and permanent interactions with the surrounding epithelial cells (Choi et al. 2017). Adipose cells are also a major component of the tumor microenvitonment and are especially prominent in the breast tumors. Cancer-associated adipocytes (CAAs) are smaller than the non-tumor-associated adipocytes and are highly secretory cells reprogrammed by the tumor cells into dedifferentiated preadipocyte stage. The role that CAAs play in tumor development is supported by epidemiological observations of higher breast cancer incidence in obese postmenopausal women (Calle \& Kaaks 2004) and associations of obesity with poorer clinical outcome (Reeves et al. 2007; Chan et al. 2014). CAAs affect cancer cells proliferation, survival and invasion potential by secreting various adipokines, lipids and reactive oxygen species (ROS) thus provoking ECM remodeling and metabolic transformations (Choi et al. 2017; Nieman et al. 2013; Berstein et al. 2007). Another component of the tumor microenvironment are the endothelial cells (tumor endothelial cells [TEC]). These cells differ from the normal epithelial cells in their responsiveness to EGF, VEGF and other growth factors, and are associated with tumor cells adhesion, invasion, and metastasis (Hida et al. 2013). Besides of the cellular components, ECM by itself plays a multifaceted role in tumor development through biochemical and biomechanical mechanisms (Yu \& Di 2017).

\section{Phyto-polyphenols with promising inhibitory effects on breast cancer metastasis}

Polyphenols (s. polyhydroxyphenols) are class of chemical compounds, broadly distributed in nature and characterized by the presence of phenol structures in their molecules. A vast group of polyphenols universally present in the plant kingdom is the bioflavonoids. Comprising more than 4000 distinct members, bioflavonoids are 15-Carbon skeleton derivatives of beno- $\gamma$-pyrone (s. phenylchromone). Flavonoids are divided into different classes that include flavonols, glavans and proanthocyanidins, anthocyanidins, flavanones, flavones, isoflavones, and noeflavonoids.

Phyto-polyphenols are integral part of the human diet. They have been also used worldwide in traditional medicine for thousands of years for their anti-bacterial, anti-viral, anti-inflammatory, anti-allergic, and anti-thrombotic properties. The effects of phyto-polyphenols are usually pleiotropic, and many of these compounds have proven anti-carcinogenic actions manifested by suppression of cancer cell transformation, differentiation, proliferation and invasiveness, angiogenesis and induction of apoptosis. The anti-carcinogenic properties of the phyto-polyphenols can be attributed to their direct effects on the activities of key protein kinases controlling tumor cell proliferation and apoptosis or to the suppression of MMP function. For example quercetin, fisetin or luteolin and other phyto-polyphenols inhibit the activity of protein kinase C (PKC). PKC plays an important role in a variety of processes in cancer, from tumor initiation and progression to inflammation and T lymphocyte function. Genistein (Akiyama et al. 1987; Peterson \& Barnes 1991; Pagliacci et al. 1994), luteolin (Huang et al. 1999; Lee et al. 2002), quercetin (Agullo et al. 1997), and butein (Yang et al. 1998) affect tumor development by suppressing the activity of epidermal growth factor receptor (EGFR) tyrosine kinase resulting in downstream effects on number of substrates such as serine/threonine kinases, mitogen-activated protein kinases (MAPKs), and rapidly accelerated fibrosarcoma kinases (RAFs) (Carpenter \& Cohen 1990). Another protein tyrosine kinase that is targeted by phyto-polyphenols (luteolin, quercetin, etc.) is the focal adhesion kinase (FAK) (Kanadaswami et al. 2005). FAK is a key molecule in signaling pathways essential for the cell cycle, survival, and motility.

Whole extracts or specific polyphenols derived from green tea or grape vines have been shown to possess anti-carcinogenic and anti-metastatic properties in multiple in vitro and in vivo studies. Extracts from peach (Prunus persica) (Noratto et al. 2014), olive (Olea europaea) (Hassan et al. 2012), promegranate (Punica granatum) 
(Kim et al. 2002), evening primrose (Oenothera paradoxa) (Lewandowska et al. 2013a; Lewandowska et al. 2013b), the spotted (s. prostrate) spurge (Euphorbia suprina, (s. E. maculata)) (Ko et al. 2015), Japanese quince (Chaenomeles japonica) (Lewandowska et al. 2013c), Himalayan rhubarb (Rheum emodi) (Kumar et al. 2015; Naveen Kumar et al. 2013) or Phyllanthus sp. (P. niruri, P. urinaria, P. watsonii, $P$. amarus) (Lee et al. 2011), and others inhibit tumor growth and suppress breast cancer metastasis.

\section{Grape polyphenols}

Grape vine plant consists of three main species: the European grapes (Vitis vinifera), the North American grapes ( $V$. lanrusca and $V$. rotundifolia), and French hybrids. Grape vines belong to the Vitaceae family and were domesticated as early as in the Neolithic period. Grapes contain variety of polyphenolic compounds largely anthocyanins, flavonols (catechin, epicatechin, quercetin, procyanidin polymers), stilbenes (resveratrol), and phenolic acids. Grape polyphenols are distributed mostly in the seed, skin, leaf and the stem of the plant, and in considerably less amount in its juicy middle section. Resveratrol, quercetin and catechin polyphenols represent about $70 \%$ of the polyphenols present in the grape plant and have the most potent anti-carcinogenic activities (Damianaki et al. 2000). Importantly, grape polyphenols are easily absorbed and metabolized in the body in their intact form (Soleas et al. 2002). Experimental data demonstrate that grape polyphenols have cardio- and neuro-protective, anti-microbial (Lagneau et al. 1998; Xia et al. 2010; Castillo-Pichardo et al. 2013), anti-oxidant (Torres et al. 2002; Negro et al. 2003; Makris et al. 2007) and variety of anti-carcinogenic (anti-proliferative, pro-apoptotic, anti-invasive, anti-angiogenic, antioxidant, and cancer-preventive) properties (Soleas et al. 2002; Asensi et al. 2002; Nifli et al. 2005; Morré \& Morré 2006; Hakimuddin et al. 2008; Gulati et al. 2006; Kim et al. 2004; Dechsupa et al. 2007; Aggarwal \& Shishodia 2006; Kaur et al. 2009).

The suppressing effects of the grape polyphenols on breast cancer initiation and cell growth are demonstrated in multiple in vitro and in vivo systems (Singletary et al. 2003; Hakimuddin et al. 2004) (Singh et al. 2004) (Schlachterman et al. 2008). Using nude mice xenografted with GFP-tagged highly metastatic ER-negative MDA-MB-468 breast cancer cells, Castillo-Pichardo et al. (2009) found that low concentrations of grape polyphenols can inhibit breast cancer metastasis initiation, specifically to liver and bone. Experiments using BALB/c 4 T1 mammary xenograft mouse model showed that treatment with dietary grape skin extracts in drinking water resulted in decrease of lung metastasis incidence and stimulate cell survival (Sun et al. 2012). Resveratrol, quercetin and catechin are particularly important in estrogen receptor (ER)-positive breast tumors since they also act as selective estrogen receptor modulators (SERMs) (Harris et al. 2005). Grape polyphenols exert their effects by modulating the activities of Akt, extracellular-signal-regulated kinases (ERKs), and MAPKs (Lu et al. 2009; Kaur et al. 2011; Sun et al. 2012). These polyphenols inhibit the expression and activity of EGFR1 and EGFR2 ( $s$. HER2) (Azios \& Dharmawardhane 2005; Fridrich et al. 2008), and elevated EGFR tumor expression is generally associated with higher cancer progression and metastasis (Buret et al. 1999). HER2 plays a major role in the metastatic process and its overexpression is often observed in metastatic cancers. Inhibition of HER2 by grape polyphenols leads to inhibition of phosphatidylinositol-3-kinase (PI3K)/Akt and mammalian target of rapamycin (mTOR) as well as activation of 5' AMP-activated protein kinase (AMPK) - all of these enzymes are involved in the process of metastasis. Additionally, grape polyphenols upregulate forkhead box O1 (FOXO1) and І ІкB $\alpha$ thus inhibiting NF-kB activity (Castillo-Pichardo et al. 2009).

\section{Resveratrol}

Resveratrol (3,5,4' -trihydroxy-trans-stilbene) is a stilbenoid and phytoalexin produced by grapes, peanuts, berries, and the Japanese "Kojokon" (Polygonum cuspidatum) in response to injury or pathogen invasion (Burns et al. 2002). Chemically, resveratrol is a precursor of a family of polymers named viniferins. It quickly enters the bloodstream from the gastro-intestinal tract, reaching significant plasma concentrations (Bhat et al. 2001). Resveratrol has been used for centuries in the traditional Asian medicine since it has broad range of effects, including anti-oxidant properties, modulation of lipid and lipoprotein metabolism, anti-platelet aggregation, vaso-relaxation, wound-healing, estrogenic activities and multiple anti-carcinogenic effects. The anti-carcinogenic properties of resveratrol have been demonstrated in many types of cancer including those of the breast (Fig. 1) (Delmas et al. 2006; Busquets et al. 2007; Castillo-Pichardo et al. 2009). They include tumor cell proliferation arrest, induction of apoptosis, suppression of tumor cell mobility and migration, prevention of tumor-derived nitric oxide synthase expression, inhibition of tumor progression, etc. (Jang et al. 1997; Nakagawa et al. 2001; Garvin et al. 2006) Resveratrol is a SERM that acts in different tissues as a pro- or anti-estrogen (Bowers et al. 2000).

Current literature exploring the in vivo doses of resveratrol needed to achieve beneficial anti-carcinogenic effect is still not consolidated. In fact, low doses of reservatrol achievable from dietary sources (such as red wine) seem to be sufficient in suppressing tumor growth (Tessitore et al. 2000). Resveratrol might be an effective chemopreventive agent and the mechanism behind this effect includes direct inhibition of cyclooxygenase 


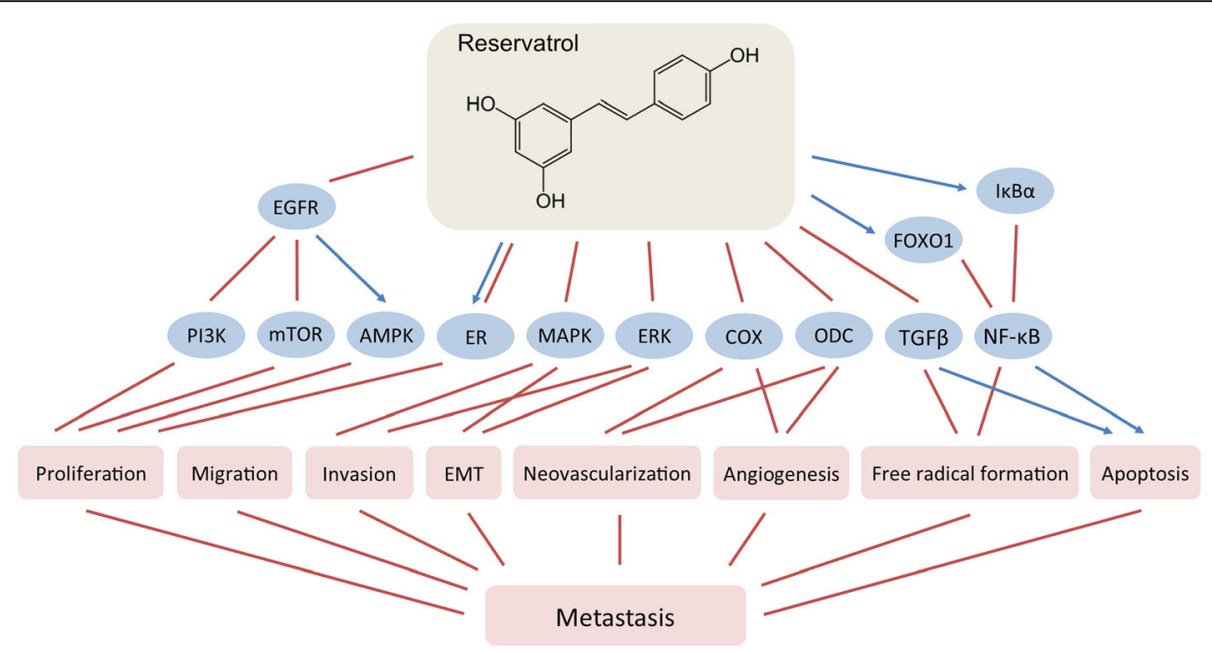

Fig. 1 Effects of reservatrol on breast cancer metastasis

(COX) activity and indirect suppression of ornithine dacarboxylase (ODC) (Jang et al. 1997; Subbaramaiah et al. 1999; Baur \& Sinclair 2006). The effect of resveratrol on COX and ODC activities could also explain its anti-neovascularization and anti-angiogenic properties.

In vitro and in vivo studies have showed that resveratrol inhibits NF- $\kappa B$ and decreases its DNA binding resulting in modulation of transcription of genes involved in tumor growth and metastasis (Tsai et al. 1999; Banerjee et al. 2002; Benitez et al. 2009). Results from a study using Sprague-Dawley rats where resveratrol was given in the diet two weeks before vein injection with the tumor-initiating agent 7,12-dimethylbenz(a)anthracene (DMBA) demonstrated that resveratrol acts as a strong antioxidant and significantly induces apoptosis with concomitant upregulation of TGF $\beta 1$ expression and inhibition of NF- $\mathrm{kB}$ in these carcinogen-challenged animals (Chatterjee et al. 2011). Experiments using female FVB/N HER2/neu transgenic mice spontaneously developing mammary tumors revealed significant reduction of lung metastases incidence after oral resveratrol supplementation (Provinciali et al. 2005). Contrary to the previous results, resveratrol was found to promote tumor growth and metastases incidence in immunocompromised mice grafted with low-metastatic ER $\alpha$-negative/ER $\beta$-positive MDA-MB-231 or highly-metastatic $E R \alpha / E R \beta$-negative MDA-MB-468 breast cancer cells (Castillo-Pichardo et al. 2013). The reason for the discrepancy between the experimental in vivo data may be explained with the different protocols followed for drug administration, the variable concentration of reservatrol used or combination of multiple other factors.

Besides acting on tumor cells, reservatrol have modulating effects on tumor microenvironment. It induces $\mathrm{CD} 8^{+}$ $\mathrm{T}$ cells antitumor immunity, decreases the percentage of Tregs in the tumor, increases the levels of interferon-gamma
(IFN $\gamma$ ) and reduces those of IL-6, IL-10, and VEGF, as shown in renal tumor model (Chen et al. 2015). Reservatrol also reduces oxidative stress by acting as a direct scavenger of ROX, by inhibiting NADPH oxidase expression or xanthine oxidase activity (Pelicano et al. 2004; Lin et al. 2000), or by increasing sirtuin 1 (SIRT1) activity (Xu et al. 2012).

In summary, although the anti-carcinogenic and cancer-preventive properties of resveratrol are proven in multiple studies, the real efficacy of this compound in vivo is still unclear. The clinical evidence for resveratrol as an effective supplement for cancer prevention and treatment is scarce as at this time there is very little clinical data for the efficacy of resveratrol in cancer treatment.

\section{Green tea polyphenols}

Green tea is a product of leafs and the leaf buds of Camellia sinensis plant that belongs to Theacea family. Green tea contains more than 200 bioactive compounds, among them polyphenols (catechins and flavonols), alkaloids (caffeine), amino acid analogs (theanine), vitamins, minerals, etc. Polyphenols are the largest and most active group of chemical compounds in the green tea comprising about $40 \%$ of the leave dry weight. Polyphenols found in green tea include: epigallocatechin-3-gallate (EGCG) (48.6\%), epicathechin gallate (ECG) (12.3\%), epigallocatechin (EGC) (4.1\%), epicatechin (EC) (4.1\%), gallocatechin gallate (GCG) $(1.8 \%)$, gallocatechin (GC) (1.8\%), catechin (1.2\%), and gallic acid (0.2\%) (Slivova et al. 2005).

Green tea polyphenols demonstrate beneficial effects in different pathological conditions including obesity, diabetes and cancer. Polyphenols contained in the green tea were also found to inhibit tumor growth and 
invasion of cancers such as leukemia, those of prostate, lung, liver, and breast (Dreosti et al. 1997; Isemura et al. 1993) (Sartippour et al. 2001). In vitro studies using human MDA-MB-231 and MCF-7 breast cancer cells showed downregulation of MMP-2 and -9, EGFR and upregulation of TIMP-1 and -2, involvement of FAK/ ERK/NF- $k B$ signaling pathways with concomitant inhibition of cellular invasion (Farabegoli et al. 2011; Sen et al. 2010). Aqueous extract of green tea induced apoptosis and inhibited cell proliferation, migration and invasion in metastasis-specific mouse mammary carcinoma 4 T1 cells in vitro. Green tea extract was effective in vivo in decreasing tumor weight and significantly reduced lung and liver metastases incidence in female BALB/c mice bearing $4 \mathrm{~T} 1$ tumors (Luo et al. 2014). In vivo, green tea polyphenols inhibited the development and progression of lung, prostate, esophagus, stomach, intestine, skin, and other cancers (Katiyar \& Mukhtar 1996; Yang et al. 2002). The induction of apoptosis by green tea polyphenols was found to be driven by mitochondria-targeted, caspase 3-executed mechanism (Hsu et al., 2003). The anti-invasive properties of the green tea polyphenols in breast cancer might be a result of preventing the formation of molecular complexes controlling cell adhesion and migration, specifically inhibition of activator protein-1 (AP-1) and NF- $\mathrm{kB}$ and consequent suppression of uPA secretion (Slivova et al. 2005).

Epidemiological studies, though inconclusive, suggest possible cancer preventive action of the green tea polyphenols. Nevertheless the beneficial effect of tea consumption for cancer prevention or progression is doubtful. In order to reach sufficient serum concentrations, high doses of polyphenols consumption are needed. Still, regular consumption of green tea has been associated with better prognosis in breast cancer patients (Nakachi et al. 1998) and possibly a decreased risk of recurrence (Inoue et al. 2001).

\section{Epigallocatechin gallate (EGCG)}

EGCG is the ester of epigallocatechin and gallic acid and it is the most abundant polyphenol in the green tea. In addition to green tea, EGCG is present in trace amounts in apples, plums, onions, hazelnuts, pecans, etc.

Experimental data demonstrate that EGCG inhibits tumor cell proliferation, adhesion and invasion and induces apoptosis in variety of cancers including those of the breast (Fig. 2) (Ahmad et al. 1997; Yang et al. 2009; Shammas et al. 2006). Treatment of $4 \mathrm{~T} 1$ cells with EGCG decreases Bcl-2 expression and mitochondrial disruption thus releasing cytochrome $\mathrm{C}$ as well as upregulating Apaf-1, leading to the cleavage of caspase 3 and poly [ADP-ribose] polymerase (PARP) proteins (Baliga et al. 2005). In the same study, oral administration of green tea polyphenols to 4 T1-xenografted BALB/c

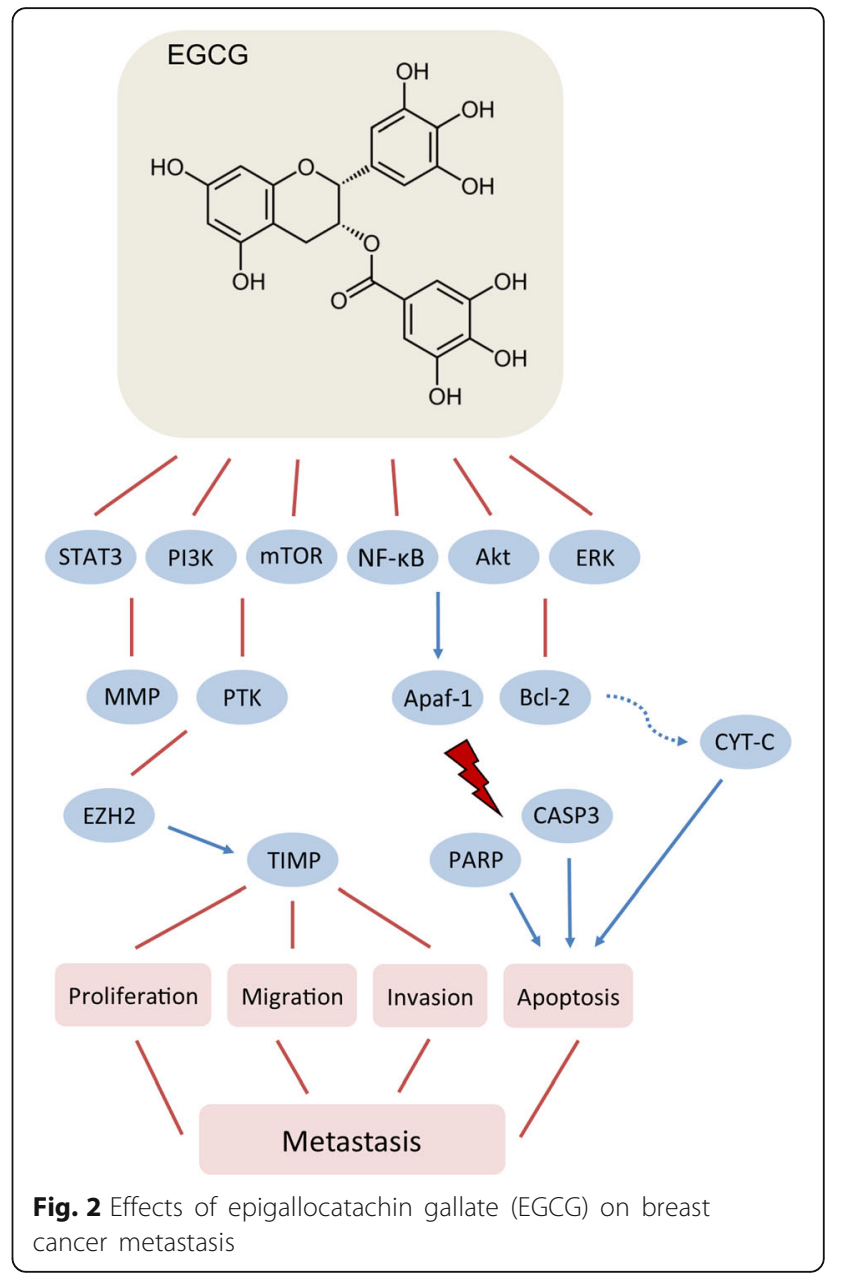

mice resulted in reduction of tumor growth and lung metastasis incidence. The $67-\mathrm{kDa}$ laminin receptor (67LR) has been identified as an essential cell surface target for EGCG action (Tachibana et al. 2004; Umeda et al. 2008). The mechanism of the tumor-suppressive and anti-metastatic actions of EGCG is a result of involvement of Akt/eNOS/NO/ cGMP/PKC $\delta$ signaling cascade (Kumazoe et al. 2013). Similarly to other polyphenolic compounds, the effect of EGCG in cancer cells is pleiotropic. It inhibits the activities of PTKs (EGFR, FGFR, PDGFR, HER2/neu tyrosine kinases) and Akt kinase (Liang et al. 1997; Pianetti et al. 2002) via STAT3, PI3K, mTOR, and NF-kB signaling pathways (Masuda et al. 2002; Van Aller et al. 2011). Results from in vitro study by using MDA-MB-231 cells demonstrated that EGCG modulates cell matrix adhesion molecules and growth factor receptors through FAK/ERK signaling pathway mechanism (Sen \& Chatterjee 2011). IGCG also inhibits the expression and activities of MMP-2 and -9 (Sen et al. 2009; Yang et al. 2005; Sen et al. 2010) (Farabegoli et al. 2011), and this seems to be the main driver for its anti-metastatic actions (Yang \& Wang 1993). The inhibition of 
MMPs can be explained by the fact that EGCG suppresses FAK, PI3K, and ERK which further leads to downregulation of EGF (Sen \& Chatterjee 2011). In addition, the suppression of MMPs involves epigenetic induction of TIMP-3 levels through inhibition of the enhancer of zeste homolog 2 (EZH2) and class I histone deacetylases (HDACs) (Deb et al. 2014). Short-term supplementation with the active compounds in green tea in men with prostate cancer showed that EGCG significantly reduces serum levels of VEGF (McLarty et al. 2009). Based on experimental data, it appears that plasma concentrations of EGCG comparable to those observed in regular green tea consumers are sufficient to inhibit MMPs and thus to affect negatively the invasion potential and metastasis in breast cancer patients (Garbisa et al. 2001).

In addition of suppressing tumor growth, ECGC was found to modulate tumor microenvironment by reducing TAM infiltration (Jang et al. 2013). In the same study, ex vivo incubation of TAM with exosomes from ECGC-treated mouse mammary tumor 4 T1 cells skewed macrophages from tumor-promoting M2-like to tumor-inhibitor M1-like phenotype (Jang et al. 2013). Further, EGCG targets tumor microenvironment by preventing and reversing the advancement of fibroblast-mediated effects by inhibiting signaling cascades downstream of TGF $\beta$ (Gray et al. 2014).

\section{Other phyto-polyphenols}

Along with the above discussed phyto-polyphenols, a number of other compounds have been investigated for their anti-carcinogenic properties, including anti-metastatic actions. Plants rich in these polyphenolic compounds have been used for centuries in culinary and traditional medicine.

\section{Kaempferol}

Kaempferol (3,5,7-Trihydroxy-2-(4-hydroxyphenil)-4H-chromen-4-one) is a naturally occurring flavonol in broad range of plants from Pteridophyta, Pinophyta and Angiospermae divisions. Among the commonly consumed foods containing kaempferol are grapes, green tea, apples, tomatoes, potatoes, onions, broccoli, squash, Brussels sprouts, cucumbers, lettuce, green beans, peaches, blackberries, raspberries, spinach, etc. Kaempferol is actively absorbed in the small intestine and can be found in the plasma in nanomolar concentrations (Calderón-Montaño et al. 2011). This polyphenol is easily metabolized in the liver and is delivered to various other organs in the form of glucuronides and sulfoconjugates (Calderón-Montaño et al. 2011).

To date, kaempferol has been shown to exert a variety of effects including antioxidant, anti-inflammatory, anti-microbial, anxiolytic, anti-allergic as well as anti-carcinogenic and cancer preventive activities (Calderón-Montaño et al. 2011). Multiple in vitro and in vivo studies demonstrated that kaempferol has pleiotropic effects in cancer targeting cancer cell proliferation, apoptosis and mobility, tumor growth, angiogenesis and metastasis (Fig. 3) (Kim \& Choi 2013; Calderón-Montaño et al. 2011; Boam 2015; Srinivas 2015). Kaempferol is an endocrine-disruptor that influences the activity of ER, having both, estrogenic and anti-estrogenic properties (Calderón-Montaño et al. 2011). This makes kaempferol potentially useful in ER-positive breast cancers, where it suppresses tumor growth by ER-dependent mechanism (Oh et al. 2006).

Kaempferol interacts with major signaling pathways such as ERK1/2 (Aiyer et al. 2012), MAPK (Li et al. 2015), and p53 (Calderón-Montaño et al. 2011), and is a potential anti-metastasis agent. It inhibits the invasion, adhesion, and migration of U-2 osteosarcoma cells (Chen et al. 2013). Anti-metastatic effects of kaempferol were observed in SCC4 oral cancer cells where it downregulated MMP-2 and TIMP-2 mRNA and protein expression by suppressing c-Jun activity (Lin et al. 2013). Recent study found that kaempferol inhibits MDA-MB-231 breast cancer cell adhesion, migration and invasion, and reduces lung metastasis incidence in mice (Li et al. 2015).

The mechanisms behind the anti-metastatic effects of kaempferol include supression of MMPs (MMP-2 and MMP-9) and uPA expression and activity via ERK, p38, JNK, and MAPK signaling (Chen et al. 2013). Kaempferol inhibits the translocation of the MAPK upstream regulator $\mathrm{PKC} \delta$ from the cytoplasm to the plasma membrane where it is physiologically active, thus suppressing MAPK signaling pathway (Li et al. 2015). Another mechanism by which kaempferol suppress metastasis is by inhibiting VEGF production as demonstrated in ovarian cancer OVCAR-3 cells in vitro (Luo et al. 2008). In the same cell line, kaempferol was also shown to downregulate cMyc and promote apoptosis (Luo et al. 2010). Additionally, kaempferol inhibits lymphangiogenesis, which is an integral step in the metastatic process. It reduces the density of tumor-associated lymphatic vessels as well as the incidence of lymph node metastases in breast cancer xenograft models in a VEGFR2/3 kinase manner (Astin et al. 2014).

\section{Curcumin}

Curcumin (s. diferuloylmethane, E100 (Natural Yellow 3)) ((1E,6E)-1,7-Bis(4-hydroxy-3-methoxyphenyl)-1,6-heptadiene-3,5-dione) is a natural diarylheptanoid polyphenol derived from turmeric plant (Curcuma longa) belonging to the ginger family (Zingiberaceae). Turmeric is common ingredient of the traditional Indian cuisine (main ingredient of curry) as well as it is used worldwide as a food additive for coloring (bright-yellow agent E100). Additionally, turmeric is known for its medicinal properties. 


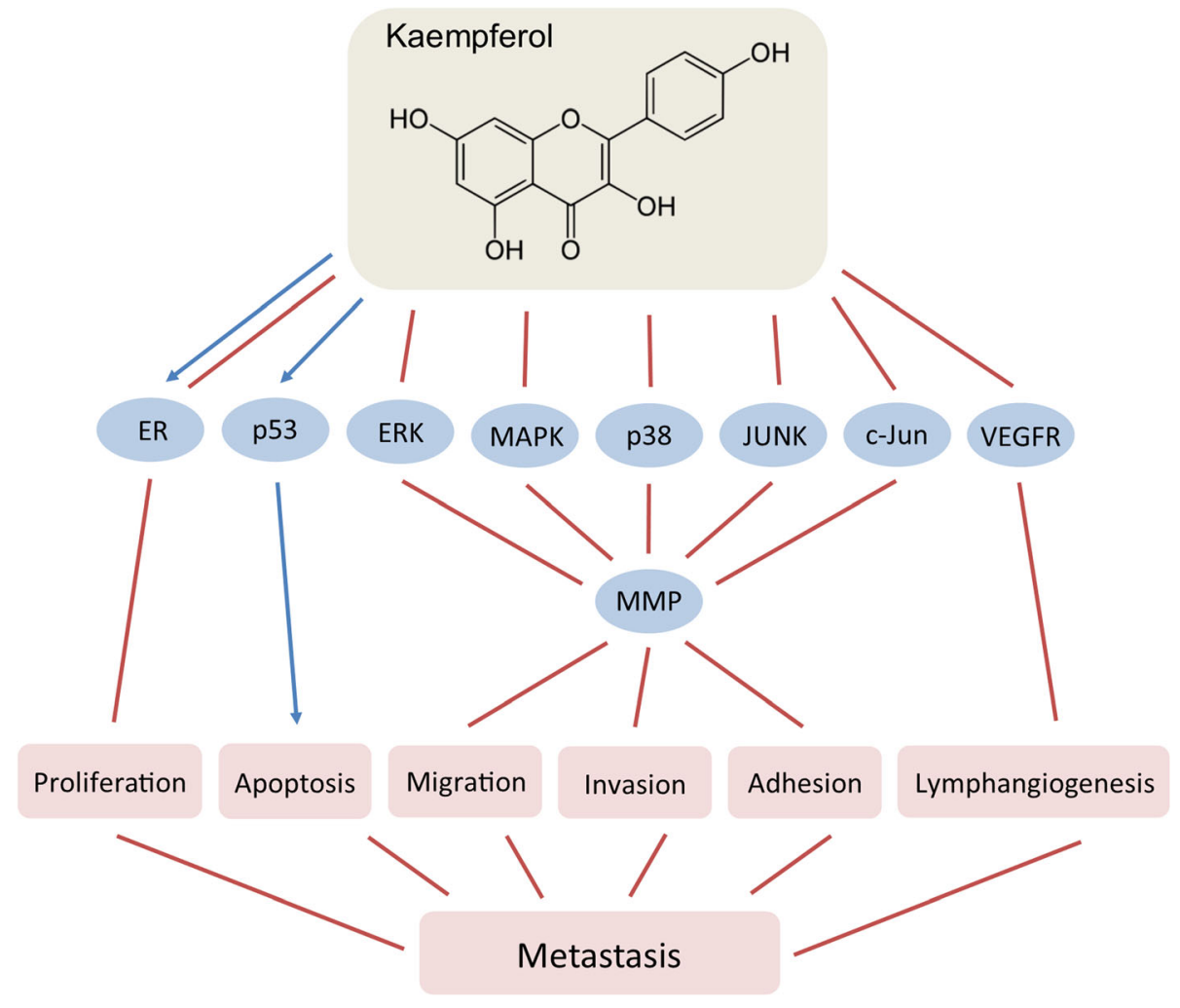

Fig. 3 Effects of kaempferol on breast cancer metastasis

Powdered turmeric underground stems (rhizomes) have been used for more than 6000 years for treating broad range of conditions related to inflammation, allergies, parasitic infections, respiratory diseases, diabetes, neurodegenerative diseases and many others. Turmeric-derived curcumin has also well established anti-carcinogenic activities on cell transformation, proliferation, apoptosis, survival, invasion, metastasis, adhesion as well as angiogenesis. The anti-carcinogenic effects of curcumin have been demonstrated in different studies on hematogenous, multiple myeloma, glioblastoma, skin, head and neck, lung, colon, prostate, breast, and other types of cancer (Bachmeier et al. 2007; Kuo et al. 1996; Sung et al. 2009; Dhandapani et al. 2007; Limtrakul et al. 1997; Wilken et al. 2011; Moghaddam et al. 2009; Chen et al. 1999; Kawamori et al. 1999; Johnson \& Mukhtar 2007; Chendil et al. 2004; Mehta et al. 1997; Huang et al. 1998; Killian et al. 2012).

Curcumin is poorly metabolized and extensively excreted. It can be found in low concentrations in plasma and variety of tissues (Anand et al. 2007). Despite its lower bioavailability, curcumin in low concentrations has been shown to possess toxicity selectively to cancer, but not to untransformed cells (Syng-Ai et al. 2004). For example, experimental data showed that human multidrug-resistant breast cancer MCF-7/TH cells are approximately 3.5-fold more sensitive to curcumin than the non-carcinogenic epithelial MCF-10A cells (Ramachandran \& You 1999).

The anti-carcinogenic properties of curcumin are pleiotropic and are based on its effects on both, the tumor cells and the tumor microenvironment. For example, curcumin can modulate inflammatory pathways and tumor progression and metastasis, affecting tumor cell survival, proliferation, and invasiveness (Gupta et al. 2010). Curcumin as well as other plant-derived natural polyphenols such as EGCG or resveratrol, induce epigenetic changes (inhibition of DNA methyltransferases (DNMTs), regulation of histone acetyltransferases (HATs) and HDACs, or microRNA modulation) (Gonwa et al. 1989) that lead to suppression of EMT and metastasis (Bandyopadhyay 2014; Bachmeier et al. 2007; Kunnumakkara et al. 2008).

The anti-metastatic action of curcumin involves inhibition of MMP-2, - 9, and MT1-MMP (Ohashi et al. 2003; Kim et al. 2012) (Fig. 4). Curcumin acts as specific supressor of p300/CREB-binding protein and affects major signalling pathways, protein tyrosine kinases and cytokines such as MAPK (Kim et al. 2012), JAK2/STAT3, Src/Akt (Saini et al. 2011), c-Jun/AP-1 (Collett \& Campbell 2004), PKC (Garg et al. 2008), sonic hedgehog (Elamin et al. 2010), CXCL1 and 2 (Killian et al. 2012), etc. It also inhibits HDACs 1,3 , and 8 and HATs enzyme 


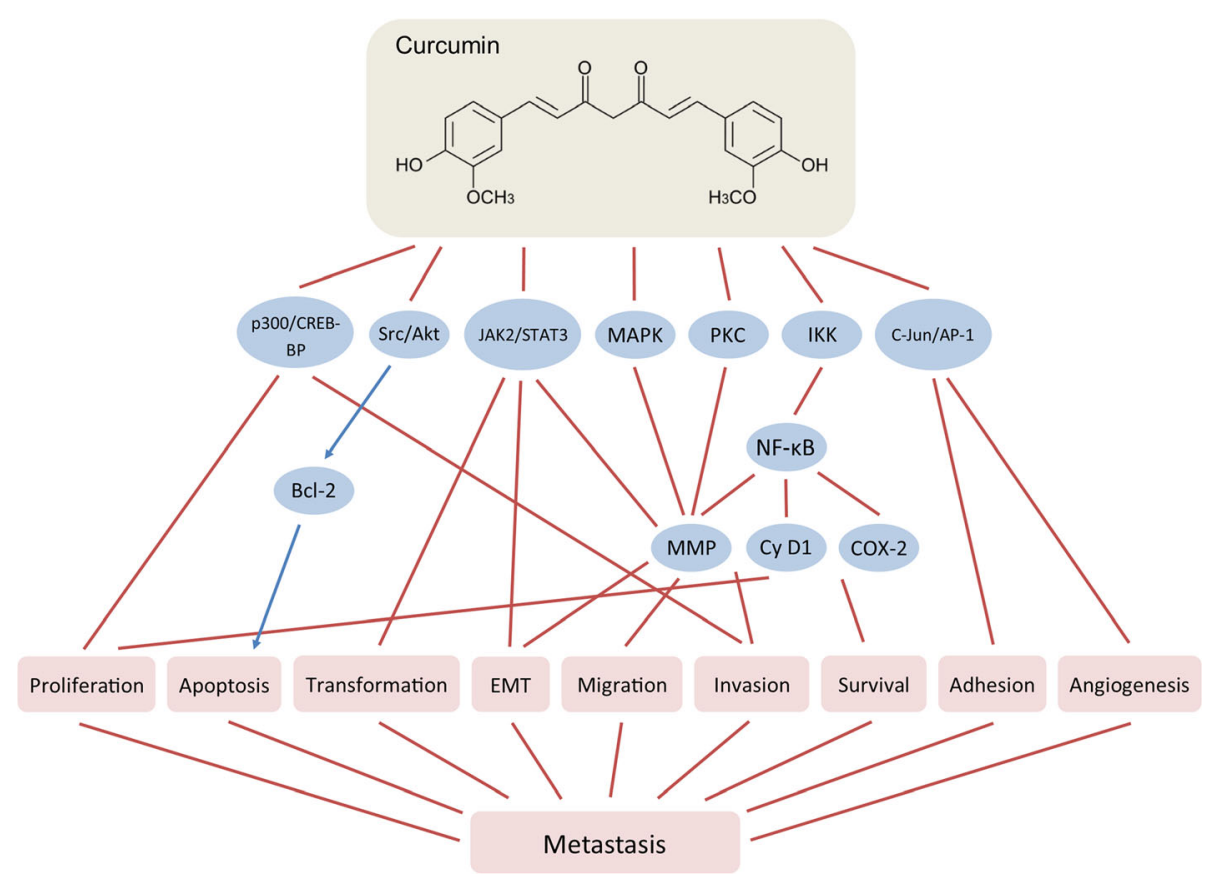

Fig. 4 Effects of curcumin on breast cancer metastasis

activities and modulates chromatin modification (Balasubramanyam et al. 2004; Reuter et al. 2011). In addition, curcumin suppresses NF- $\mathrm{kB}$ signaling by negative modulation of IKK, either directly or through action of its upstream activators (Bharti et al. 2003; Jobin et al. 1999), preventing in such a way phosphorylation of IкB (Plummer et al. 1999). Curcumin abolishes the DNA binding of NF- $\mathrm{KB}$ and inhibits reporter gene expression in $\mathrm{H} 1299$ non-small cell lung carcinoma cell line, thus downregulating MMP-9 activation (Shishodia et al. 2003). In mice, where MDA-MB-231 breast cancer cells were injected intracardiac, oral curcumin administration significantly reduced the number of lung metastases (Bachmeier et al. 2007). This effect was most likely a result of inhibition of NF- $\mathrm{KB}$ activity and transcriptional downregulation of AP-1 and downregulation of cyclin D1, COX-2, and MMP-9, which further leads to inhibition of the breast cancer cell metastasis (Aggarwal et al. 2005; Kim et al. 2012).

Chronic inflammation is considered to be a major factor in tumor progression. For example, chronic prostatitis, chronic obstructive pulmonary disease, inflammatory bowel disease or chronic pancreatitis - all represent risk factors for developing prostate, lung, colon or pancreatic cancer. Curcumin inhibits chronic inflammation by disrupting the feedback loop between NF- $\mathrm{BB}$ and the pro-inflammatory cytokines, CXCL-1 and -2 (reviewed by Bandyopadhyay (Bandyopadhyay 2014)).
By inhibiting NF-kB signaling, curcumin suppresses metastasis in the very early stages of EMT. In lipopolysaccharide (LPS)-induced EMT in MCF-7 and MDA-MB-231 cells, curcumin downregulated the expression of vimentin and upregulated those of E-cadherin as well as inhibited LPS-induced morphological transformation of the cells through inactivation of NF-kB-SNAIL signaling pathway (Huang et al. 2013).

Curcumin acts also as a phytoestrogen (Bachmeier et al. 2010). The anti-proliferative effects of curcumin were found to be estrogen-dependent in ER-positive MCF-7 counteracting the estrogen responsive element (ERE)-CAT activities of estradiol (Shao et al. 2002). HER2/neu-positive or tamoxifen-resistant breast tumors are associated with specific microRNA signature, including overexpression of miR-181 (Miller et al. 2008; Lowery et al. 2009). In breast cancer, curcumin was shown to inhibit metastasis by inducing the expression of miR-181b and downregulatinng those of CXCL-1 and -2 (Kronski et al. 2014).

A variety effects on tumor microenvironment were described after curcumin treatment. In colon cancer, curcumin interacts with the stromal fibroblasts in the colon tumor microenvironment thus suppressing their crosstalk with CSCs (Buhrmann et al. 2014). Treatment with curcumin-polyethylene glycol conjugate (an amphiphilic curcumin-based micelle) suppressed the percentage of myeloid-derived suppressor cells (MDSCs), which was suggested to be the reason behind the observed 
inhibition of Treg and the activation of the effector T-cells (Lu et al. 2016). Combination of curcumin and ECGC inhibits colorectal carcinoma microenvironment-induced angiogenesis by activating JAK/STAT3/IL-8 signaling pathway (Jin et al. 2017). Curcumin downregulates the expression of VEGF as shown in prostate cancer cells (Gupta et al. 2013) and blocked IL-1 and VEGF expression in chondrosarcoma cells (Kalinski et al. 2014).

Currently, curcumin is an object of more than 120 clinical trials evaluating its effects against different maladies including cancer.

\section{Honokiol}

Honokiol is a biphenolic lignan with bioactive para-allyl and ortho-allyl phenolic groups, a product of Magnolia sp. (M. biondii, M. obovate, and M. officinalis) that demonstrates promising actions on tumor metastases. Bark or seed cones of magnolia plants has been used for centuries in the traditional Asian medicine for its anti-inflammatory, antithrombotic, anxiolytic, antidepressant, antispasmodic, antioxidant, and antibacterial effects and its protective action against hepatotoxicity, neurotoxicity and angiopathy (Fried \& Arbiser 2009; Lee et al. 2011). The anti-carcinogenic activities of honokiol range from tumor suppression, pro-apoptotic and anti-angiogenic effects, and inhibition of cancer metastasis incidence by effects on tumor proliferation, migration and invasion. These properties have been demonstrated in various cancer types such as sarcoma (Nagase et al. 2001; Su et al. 2013), multiple melanoma (Ishitsuka et al. 2005), leukemia (Hirano et al. 1994; Hibasami et al. 1998; Battle et al. 2005), lung (Yang et al. 2002; Singh \& Katiyar 2013), skin (Konoshima et al. 1991), pancreas (Bai et al. 2003), ovary (Li et al. 2008), prostate (Shigemura et al. 2007), colorectal (Wang et al. 2004), breast (Nagalingam et al. 2012; Avtanski et al. 2014), and other cancers (Nagase et al. 2001; Garcia et al. 2008; Deng et al. 2008; Chen et al. 2011; Chang et al. 2013). One important characteristic of honokiol is that it easily crosses the blood-brain barrier and achieves significant serum concentrations because of its hydrophobic and lipophilic properties (Wang et al. 2011; Lin et al. 2012; Woodbury et al. 2013).

Honokiol has pleiotropic effects in the cells (Fig. 5), including modulation of NF- $\mathrm{KB}$ (Tse et al. 2005; Lee et al. 2005; Ahn et al. 2006; Sheu et al. 2008; Arora et al. 2011), MAPK (Kim et al. 2012; Zhang et al. 2014), STAT3 (Rajendran et al. 2012; Avtanski et al. 2014), Akt [238,], VEGF (Wen et al. 2015), ERK (Zhu et al. 2014; Yeh et al. 2016), s-Scr (Park et al. 2009), and

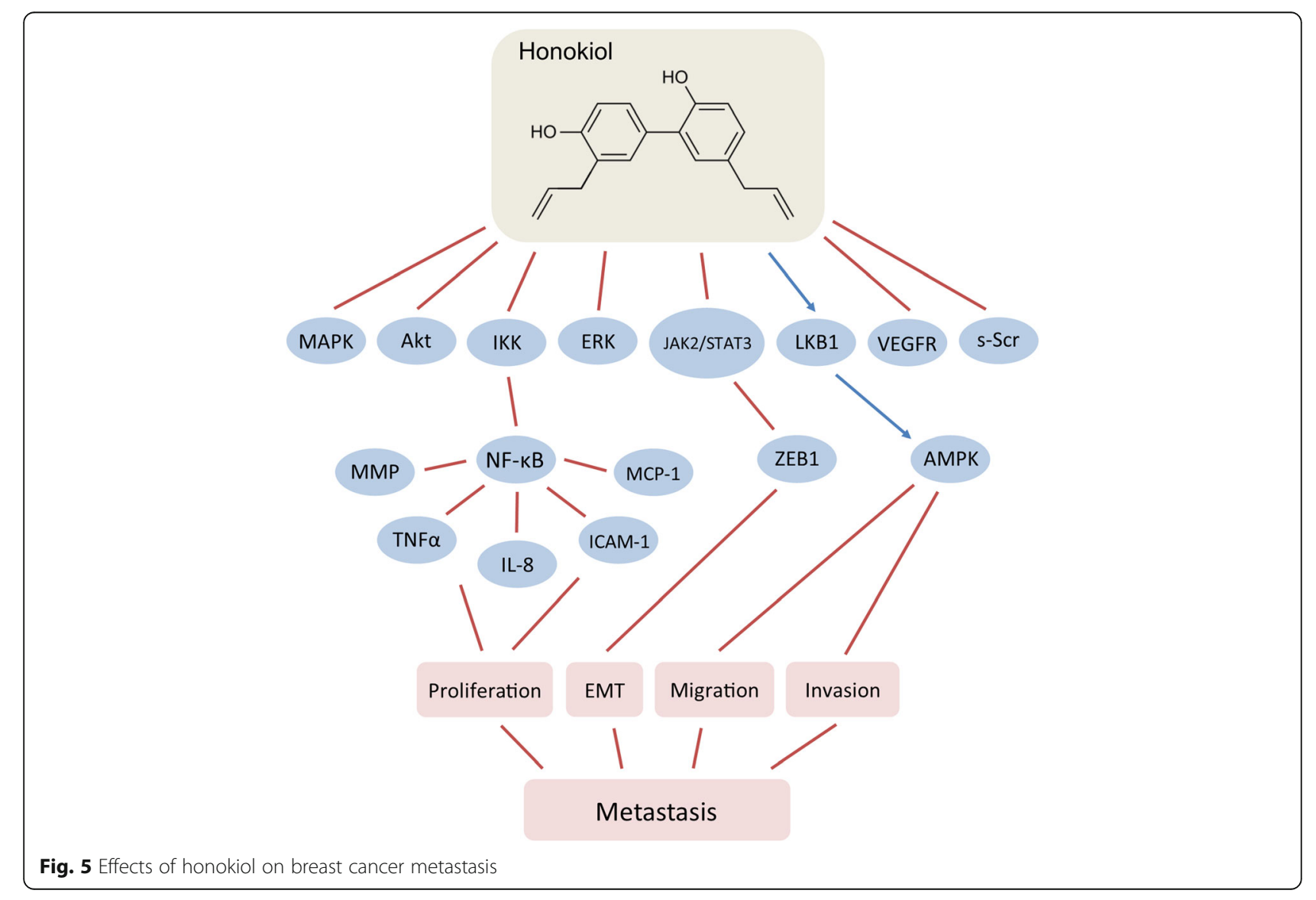


other major signaling pathways (Fried \& Arbiser 2009). For example, in SVR angiosarcoma cells, honokiol induces apoptosis by suppressing the phosphorylation of ERK, Akt, and c-Src (Bai et al. 2003). In addition to its anti-proliferative properties, honokiol inhibits the migration and tube formation of human umbilical vein endothelial cells (HUVECs) and suppresses angiogenesis in zebrafish angiogenesis model (Zhu et al. 2011). Honokiol downregulates IKK activation and thus inhibits NF- $\mathrm{KB}$ signaling pathway and MMP-9, TNFo, IL-8, ICAM-1, and MCP-1 expression (Tse et al. 2005; Lee et al. 2005; Ahn et al. 2006; Sheu et al. 2008). It also inhibits the migration and invasion of MCF-7 and MDA-MB-231 cells by upregulating the activity of liver kinase B1 (LKB1) leading to activation of AMP-activated protein kinase (AMPK) (Nagalingam et al. 2012). In vivo, honokiol inhibited tumor growth of MDA-MB-231 cells-xenografted nude mice by blocking breast cancer cellular proliferation (Nagalingam et al. 2012). Our in vitro and in vivo studies revealed that honokiol inhibits EMT of breast cancer cells by suppressing STAT3 signaling resulting in repression of ZEB1 expression and its recruitment on the E-cadherin promoter (Avtanski et al. 2014). Honokiol modulated microRNA profile in the breast cancer cell, specifically amplifying miR-34a expression in a STAT3-dependent manner, inhibiting Wnt1-metastatic-associated protein 1 (MTA1)- $\beta$-catenin signaling axis (Avtanski et al. 2015a). The mechanism behind the effects of honokiol on EMT and breast cancer migration involves induction of SirT1, SirT3 and miR-34a expression and cytoplasmic localization of LKB1 (Avtanski et al. 2015b).

Aside from directly targeting tumor cells, honokiol was also demonstrated to have effects on tumor microenvironment. Honokiol decreased desmoplasia in pancreatic tumor xenografts, as characterized by reduced secretion of extracellular matrix protein (collagen I) and suppressed myofibroblast marker $\alpha$-smooth muscle actin $(\alpha-S M A)$ immunostaining (Averett et al. 2016). Findings from the same study revealed an inhibitory effect of honokiol on C-S-C chemokine receptor type 4 (CXCR4) signaling, which is known to play an important role in the crosstalk between the tumor and the stromal cells.

\section{Conclusions}

Nature is abundant in chemicals with potential therapeutic effects that are worth studying. A variety of polyphenols from plant origin demonstrate pleiotropic therapeutic properties against a broad range of pathological conditions, including different types of cancer. Such polyphenolic compounds can be viewed as promising candidates for supplements to the traditional cancer prevention and treatment modalities as well as a basis for designing novel synthetic drugs. Naturally derived plant polyphenols have been demonstrated to inhibit metastasis initiation and progression by targeting both, cancer cells and cancer microenvironment. Novel strategies for targeting metastasis aim to modulate the levels of specific microRNAs that play a role in the transformation of the malignant cells. This approach could be used against CSCs or cells undergoing EMT that are typically drug resistant ( $\mathrm{Li}$ et al. 2010). Importantly, some phyto-polyphenolic compounds have been shown to exert beneficial effects through direct modulation of specific microRNAs at low concentrations.

Natural polyphenolic compounds are usually characterized by low level of toxicity, but main disadvantage is their poor bioavailability and weak resorption reaching. In this regard, new strategies for target-specific delivery have been experimentally developed and proven to be effective. Recent advances in nano-medicine open the doors for the development of vehicles for drug delivery with long-circulation that can be used to target transformed cells. Polyphenolic compounds administered by traditional methods are not always effective because of they are poorly absorbed and extensively excreted. But the chemopreventive efficacy of these polyphenols can be significantly improved by encapsulating them into nonoparticles. Thus, integration of various disciplines such as biochemistry, molecular biology, chemistry, and nanotechnology could contribute to the development of novel therapies against breast cancer methastasis.

This paper is dedicated to the memory of Rumiana Cherneva, who lost the battle with breast cancer.

\section{Abbreviations}

67LR: 67-kDa Laminin Receptor; AMF: Autocrine Motility Factor; AMPK: $5^{\prime}$ AMP-Activated Protein Kinase; AP-1: Activator Protein-1; BCL: B-Cell Lymphoma; C/EBPa: CCAAT-Enhancer Binding Protein-Alpha; CAA: CancerAssociated Adipocyte; CAF: Cancer-Associated Fibroblast; CAM: Cell Adhesion Molecule; CCL2: Chemokine (C-C motif) Ligand 2; COX: Cyclooxygenase; CSC: Cancer Stem Cells; CXCR4: C-S-C chemokine Receptor type 4; DNMT: DNA Methyltransferase; EC: Epicatechin; ECG: Epicathechin Gallate; ECM: Extracellular Matrix; EGC: Epigallocatechin; EGCG: Epigallocatechin-3Gallate; EGF: Epidermal Growth Factor; EGFR: Epidermal Growth Factor Receptor; EMT: Epithelial-to-Mesenchymal Transition; ER: Estrogen Receptor; ERE: Estrogen Responsive Element; ERK: Extracellular-Signal-Regulated Kinase; EZH: Enhancer of Zeste Homolog; FAK: Focal Adhesion Kinase; FGFR: Fibroblast Growth Factor Receptor; FOXO1: Forkhead Box O1 Protein; GC: Gallocatechin; GCG: Gallocatechin Gallate; HAT: Histone Acetyltransferase; HDAC: Histone Deacetylase; HER2: Human Epidermal Growth Factor Receptor 2; HUVEC: Human Umbilical Vein Endothelial Cells; IFNY: Interferon-Gamma; IkB: Inhibitors of kappa B; IKK: Inhibitors of kappa B Kinase Kinases; IL: Interleukin; LKB1: Liver Kinase B1; LPS: Lipopolysaccharide; a-SMA: Alpha-Smooth Muscle Actin; MAPK: MitogenActivated Protein Kinases; MAPKK: Mitogen-Activated Protein Kinase Kinase; M-CSF: Macrophage Colony-Stimulating Factor; MDSC: Myeloid-Derived Suppressor Cells; MEKK: MAPK/ERK Kinase Kinase; miR: MicroRNA; MMP: Matrix Metalloproteinase; MSP: Motility-Stimulating Protein; mTOR: Mammalian Target of Rapamycin; NF-KB: Nuclear Factor Kappa-Light-Chain-Enhancer of Activated B Cells; NIK: Nuclear Factor Kappa-Light-Chain-Enhancer of Activated B Cells-Inducing Kinase; NFKBIA: Nuclear Factor of Kappa Light Polypeptide Gene Enhancer in B-Cells Inhibitor-Alpha; ODC: Ornithine Dacarboxylase; PAl: Plasminogen Activator Inhibitor; PARP: Poly [ADP-Ribose] Polymerase; PDGFR: Platelet-Derived Growth Factor Receptor; PI3K: Phosphatidylinositol-3Kinase; PKC: Protein Kinase C; PR: Progesterone Receptor; RAF: Rapidly Accelerated Fibrosarcoma Kinase; ROS: Reactive Oxygen Species; RTK: Receptor Tyrosin Kinase; SERM: Selective Estrogen Receptor Modulators; TEC: Tumor 
Endothelial Cells; TLL: Tumor-Infiltrating Lymphocyte; TIMP: Tissue Inhibitors of Metalloproteinases; TNFa: Tumor Necrosis Factor-Alpha; uPA: Urokinase-Type Plasminogen Activator; VEGF: Vascular Endothelial Growth Factor; XIAP: X-linked Inhibitor of Apoptosis Protein

\section{Availability of data and materials}

Data sharing not applicable to this article as no datasets were generated or analyzed during the current study.

\section{Authors' contributions}

DA drafted the manuscript. LP revised the manuscript critically. Both authors read and approved the final manuscript.

\section{Ethics approval and consent to participate}

Not applicable.

\section{Competing interests}

The authors declare that they have no competing interests.

\section{Publisher's Note}

Springer Nature remains neutral with regard to jurisdictional claims in published maps and institutional affiliations.

Received: 27 April 2018 Accepted: 27 May 2018

Published online: 05 June 2018

\section{References}

Aggarwal BB, Shishodia S. Molecular targets of dietary agents for prevention and therapy of cancer. Biochem Pharmacol. 2006;71:1397-421.

Aggarwal BB, et al. Curcumin suppresses the paclitaxel-induced nuclear factor-KB pathway in breast cancer cells and inhibits lung metastasis of human breast cancer in nude mice. Clin Cancer Res. 2005;11:7490-8.

Agullo G, et al. Relationship between flavonoid structure and inhibition of phosphatidylinositol 3-kinase: a comparison with tyrosine kinase and protein kinase C inhibition. Biochem Pharmacol. 1997:53:1649-57.

Ahmad N, Feyes DK, Nieminen A-L, Agarwal R, Mukhtar H. Green tea constituent Epigallocatechin-3-Gallate and induction of apoptosis and cell cycle arrest in human carcinoma cells. J Natl Cancer Inst. 1997;89:1881-6.

Ahn KS, et al. Honokiol potentiates apoptosis, suppresses osteoclastogenesis, and inhibits invasion through modulation of nuclear factor-kappaB activation pathway. Mol Cancer Res. 2006;4:621-33.

Aiyer HS, Warri AM, Woode DR, Hilakivi-Clarke L, Clarke R. Influence of berry polyphenols on receptor signaling and cell-death pathways: implications for breast cancer prevention. J Agric Food Chem. 2012;60:5693-708.

Akiyama T, et al. Genistein, a specific inhibitor of tyrosine-specific protein kinases. J Biol Chem. 1987:262:5592-5.

American Cancer Society. Breast Cancer Facts \& Figures 2011-2012. Atlanta: American Cancer Society, Inc:; 2011.

Anand P, Kunnumakkara AB, Newman R a, Aggarwal BB. Bioavailability of curcumin: problems and promises. Mol Pharm. 2007;4:807-18.

Arora S, et al. Honokiol arrests cell cycle, induces apoptosis, and potentiates the cytotoxic effect of gemcitabine in human pancreatic cancer cells. PLoS One. 2011;6:e21573.

Asensi $\mathrm{M}$, et al. Inhibition of cancer growth by resveratrol is related to its low bioavailability. Free Radic Biol Med. 2002;33:387-98.

Astin JW, et al. An in vivo anti-lymphatic screen in zebrafish identifies novel inhibitors of mammalian lymphangiogenesis and lymphatic-mediated metastasis. Mol Cancer Ther. 2014;13:2450-63.

Averett C, et al. Honokiol suppresses pancreatic tumor growth, metastasis and desmoplasia by interfering with tumor-stromal cross-talk. Carcinogenesis. 2016;37:1052-61.

Avtanski DB, et al. Honokiol inhibits epithelial-mesenchymal transition in breast cancer cells by targeting signal transducer and activator of transcription 3/ Zeb1/E-cadherin axis. Mol Oncol. 2014;8:565-80.

Avtanski DB, et al. Honokiol abrogates leptin-induced tumor progression by inhibiting Wnt1-MTA1- $\beta$-catenin signaling axis in a microRNA-34a dependent manner. Oncotarget. 2015a;

Avtanski DB, et al. Honokiol activates LKB1-miR-34a axis and antagonizes the oncogenic actions of leptin in breast cancer. Oncotarget. 2015b;6:29947-62.
Azios NG, Dharmawardhane SF. Resveratrol and estradiol exert disparate effects on cell migration, cell surface actin structures, and focal adhesion assembly in MDA-MB-231 human breast cancer cells. Neoplasia. 2005;7:128-40.

Bachmeier BE, et al. The chemopreventive polyphenol curcumin prevents hematogenous breast cancer metastases in immunodeficient mice. Cell Physiol Biochem. 2007;19:137-52.

Bachmeier BE, et al. Reference profile correlation reveals estrogen-like trancriptional activity of curcumin. Cell Physiol Biochem. 2010;26:471-82.

Bai X, et al. Honokiol, a small molecular weight natural product, inhibits angiogenesis in vitro and tumor growth in vivo. J Biol Chem. 2003;278:35501-7.

Balasubramanyam K, et al. Curcumin, a novel p300/CREB-binding protein-specific inhibitor of acetyltransferase, represses the acetylation of histone/nonhistone proteins and histone acetyltransferase-dependent chromatin transcription. J Biol Chem. 2004;279:51163-71.

Baliga MS, Meleth S, Katiyar SK. Growth inhibitory and Antimetastatic effect of green tea polyphenols on metastasis-specific mouse mammary carcinoma 4T1 cells in vitro and in vivo systems. Clin Cancer Res. 2005;11:1918-27.

Bandyopadhyay D. Farmer to pharmacist: curcumin as an anti-invasive and antimetastatic agent for the treatment of cancer. Front Chem. 2014;2:113.

Banerjee S, Bueso-Ramos C, Aggarwal BB. Suppression of 7,12dimethylbenz(a)anthracene-induced mammary carcinogenesis in rats by resveratrol: role of nuclear factor-kappaB, cyclooxygenase 2, and matrix metalloprotease 9. Cancer Res. 2002;62:4945-54.

Battle TE, Arbiser J, Frank D a. The natural product honokiol induces caspasedependent apoptosis in B-cell chronic lymphocytic leukemia (B-CLL) cells. Blood. 2005;106:690-7.

Baur JA, Sinclair DA. Therapeutic potential of resveratrol: the in vivo evidence. Nat Rev Drug Discov. 2006;5:493-506.

Benitez DA, Hermoso MA, Pozo-Guisado E, Fernández-Salguero PM, Castellón EA. Regulation of cell survival by resveratrol involves inhibition of NF kappa Bregulated gene expression in prostate cancer cells. Prostate. 2009;69:1045-54.

Berstein LM, et al. Signs of proinflammatory/genotoxic switch (adipogenotoxicosis) in mammary fat of breast cancer patients: role of menopausal status, estrogens and hyperglycemia. Int J Cancer. 2007;121:514-9.

Bharti AC, Donato N, Singh S, Aggarwal BB. Curcumin (diferuloylmethane) downregulates the constitutive activation of nuclear factor-kB and $1 \mathrm{kBa}$ kinase in human multiple myeloma cells, leading to suppression of proliferation and induction of apoptosis. Blood. 2003;101:1053-62.

Bhat KPL, Kosmeder JW, Pezzuto JM. Biological effects of resveratrol. Antioxid Redox Signal. 2001;3:1041-64.

Boam T. Anti-androgenic effects of flavonols in prostate cancer. Ecancermedicalscience. 2015; https://doi.org/10.3332/ecancer.2015.585.

Bowers JL, Tyulmenkov W, Jernigan SC, Klinge CM. Resveratrol acts as a mixed agonist/antagonist for estrogen receptors alpha and beta. Endocrinology. 2000;141:3657-67.

Brew K, Nagase H. The tissue inhibitors of metalloproteinases (TIMPs): an ancient family with structural and functional diversity. Biochim Biophys Acta - Mol Cell Res. 2010;1803:55-71.

Buhrmann C, et al. Curcumin suppresses crosstalk between colon cancer stem cells and stromal fibroblasts in the tumor microenvironment: potential role of EMT. PLoS One. 2014;9:e107514.

Buret A, Gall DG, Olson ME, Hardin JA. The role of the epidermal growth factor receptor in microbial infections of the gastrointestinal tract. Microbes Infect. 1999;1:1139-44.

Burns J, Yokota T, Ashihara H, Lean MEJ, Crozier A. Plant foods and herbal sources of resveratrol. J Agric Food Chem. 2002;50:3337-40.

Busquets $\mathrm{S}$, et al. Resveratrol, a natural diphenol, reduces metastatic growth in an experimental cancer model. Cancer Lett. 2007;245:144-8.

Calderón-Montaño JM, Burgos-Morón E, Pérez-Guerrero C, López-Lázaro M. A review on the dietary flavonoid kaempferol. Mini Rev Med Chem. 2011;11:298-344.

Calle EE, Kaaks R. Overweight, obesity and cancer: epidemiological evidence and proposed mechanisms. Nat Rev Cancer. 2004;4:579-91.

Carpenter G, Cohen S. Epidermal growth factor. J Biol Chem. 1990;265:7709-12.

Castellano G, et al. Activation of the osteopontin/matrix metalloproteinase-9 pathway correlates with prostate cancer progression. Clin Cancer Res. 2008; 14:7470-80.

Castillo-Pichardo L, Cubano L a, Dharmawardhane S. Dietary grape polyphenol resveratrol increases mammary tumor growth and metastasis in immunocompromised mice. BMC Complement Altern Med. 2013;13(6)

Castillo-Pichardo L, et al. Inhibition of mammary tumor growth and metastases to bone and liver by dietary grape polyphenols. Clin Exp Metastasis. 2009;26:505-16. 
Chambers AF, Groom AC, MacDonald IC. Dissemination and growth of cancer cells in metastatic sites. Nat Rev Cancer. 2002;2:563-72.

Chan DSM, et al. Body mass index and survival in women with breast cancersystematic literature review and meta-analysis of 82 follow-up studies. Ann Oncol Off J Eur Soc Med Oncol. 2014;25:1901-14.

Chang K-H, Yan M-D, Yao C-J, Lin P-C, Lai G-M. Honokiol-induced apoptosis and autophagy in glioblastoma multiforme cells. Oncol Lett. 2013;6:1435-8.

Chatterjee M, Das S, Janarthan M, Ramachandran HK, Chatterjee M. Role of 5-lipoxygenase in resveratrol mediated suppression of 7,12dimethylbenz(a)anthracene-induced mammary carcinogenesis in rats. Eur J Pharmacol. 2011;668:99-106.

Chen $\mathrm{H}$, Zhang ZS, Zhang YL, Zhou DY. Curcumin inhibits cell proliferation by interfering with the cell cycle and inducing apoptosis in colon carcinoma cells. Anticancer Res. 1999;19:3675-80.

Chen $\mathrm{H}$-J, et al. Kaempferol suppresses cell metastasis via inhibition of the ERKp38-JNK and AP-1 signaling pathways in U-2 OS human osteosarcoma cells. Oncol Rep. 2013;30:925-32.

Chen L, Yang S, Liao W, Xiong Y. Modification of antitumor immunity and tumor microenvironment by resveratrol in mouse renal tumor model. Cell Biochem Biophys. 2015;72:617-25.

Chen X-R, et al. Honokiol: a promising small molecular weight natural agent for the growth inhibition of oral squamous cell carcinoma cells. Int J Oral Sci. 2011:3:34-42.

Chendil D, Ranga RS, Meigooni D, Sathishkumar S, Ahmed MM. Curcumin confers radiosensitizing effect in prostate cancer cell line PC-3. Oncogene. 2004;23: 1599-607.

Choi J, Cha YJ, Koo JS. Adipocyte biology in breast cancer: from silent bystander to active facilitator. Prog Lipid Res. 2017;69:11-20.

Cirri P, Chiarugi P. Cancer associated fibroblasts: the dark side of the coin. Am J Cancer Res. 2011;1:482-97.

Collett GP, Campbell FC. Curcumin induces c-Jun N-terminal kinase-dependent apoptosis in HCT116 human colon cancer cells. Carcinogenesis. 2004;25:2183-9.

Damianaki $A$, et al. Potent inhibitory action of red wine polyphenols on human breast cancer cells. J Cell Biochem. 2000;78:429-41.

Deb G, Thakur VS, Limaye AM, Gupta S. Epigenetic induction of tissue inhibitor of matrix metalloproteinase-3 by green tea polyphenols in breast cancer cells. Mol. Carcinogenesis. 2014:1-15. https://doi.org/10.1002/mc.22121.

Dechsupa S, et al. Quercetin, Siamois 1 and Siamois 2 induce apoptosis in human breast cancer MDA-mB-435 cells xenograft in vivo. Cancer Biol Ther. 2007:6:56-61.

Delmas D, Lançon A, Colin D, Jannin B, Latruffe N. Resveratrol as a chemopreventive agent: a promising molecule for fighting cancer. Curr Drug Targets. 2006;7:423-42.

Deng J, et al. Involvement of p38 mitogen-activated protein kinase pathway in honokiol-induced apoptosis in a human hepatoma cell line (hepG2). Liver Int. 2008;28:1458-64.

Dhandapani KM, Mahesh VB, Brann DW. Curcumin suppresses growth and chemoresistance of human glioblastoma cells via AP-1 and NFkappaB transcription factors. J Neurochem. 2007;102:522-38.

Dreosti IE, Wargovich MJ, Yang CS. Inhibition of carcinogenesis by tea: the evidence from experimental studies. Crit Rev Food Sci Nutr. 1997;37:761-70

Elamin $\mathrm{MH}$, et al. Curcumin inhibits the sonic hedgehog signaling pathway and triggers apoptosis in medulloblastoma cells. Mol Carcinog. 2010;49:302-14.

Ewing J. Neoplastic diseases. In: A treatise on tumors: W.B.Saunders Co; 1928.

Farabegoli F, Papi A, Orlandi M. (-)-Epigallocatechin-3-gallate down-regulates EGFR, MMP-2, MMP-9 and EMMPRIN and inhibits the invasion of MCF-7 tamoxifen-resistant cells. Biosci Rep. 2011;31:99-108.

Fridrich D, Teller N, Esselen M, Pahlke G, Marko D. Comparison of delphinidin, quercetin and (-)-epigallocatechin-3-gallate as inhibitors of the EGFR and the ErbB2 receptor phosphorylation. Mol Nutr Food Res. 2008;52:815-22.

Fried LE, Arbiser JL. Honokiol, a multifunctional antiangiogenic and antitumor agent. Antioxid Redox Signal. 2009;11:1139-48.

Garbisa S, et al. Tumor gelatinases and invasion inhibited by the green tea flavanol epigallocatechin-3-gallate. Cancer. 2001;91:822-32.

Garcia A, et al. Honokiol suppresses survival signals mediated by Ras-dependent phospholipase D activity in human cancer cells. Clin Cancer Res. 2008;14:4267-74.

Garg R, Ramchandani AG, Maru GB. Curcumin decreases \{12-O-tetradecanoylphorbol13-acetate-induced protein kinase $C$ translocation to modulate downstream targets in mouse skin. Carcinogenesis. 2008;29:1249-57.

Garvin S, Ollinger K, Dabrosin C. Resveratrol induces apoptosis and inhibits angiogenesis in human breast cancer xenografts in vivo. Cancer Lett. 2006; 231:113-22.
Gonwa TA, et al. Pathogenesis and outcome of hepatorenal syndrome in patients undergoing orthotopic liver transplant. Transplantation. 1989;47:395-7.

Gray AL, Stephens CA, Bigelow RLH, Coleman DT, Cardelli JA. The polyphenols (-)-epigallocatechin-3-gallate and luteolin synergistically inhibit TGF- $\beta$ induced myofibroblast phenotypes through RhoA and ERK inhibition. PLoS One. 2014;9:e109208.

Gulati N, Laudet B, Zohrabian VM, Murali R, Jhanwar-Uniyal M. The antiproliferative effect of quercetin in cancer cells is mediated via inhibition of the PI3K-Akt/PKB pathway. Anticancer Res. 2006;26:1177-81.

Gupta A, Zhou CQ, Chellaiah MA. Osteopontin and MMP9: associations with VEGF expression/secretion and angiogenesis in PC3 prostate Cancer cells. Cancers (Basel). 2013;5:617-38.

Gupta GP, Massagué J. Cancer metastasis: building a framework. Cell. 2006;127: 679-95.

Gupta SC, Kim JH, Prasad S, Aggarwal BB. Regulation of survival, proliferation, invasion, angiogenesis, and metastasis of tumor cells through modulation of inflammatory pathways by nutraceuticals. Cancer Metastasis Rev. 2010;29: 405-34.

Haanen JBAG, et al. Melanoma-specific tumor-infiltrating lymphocytes but not circulating melanoma-specific T cells may predict survival in resected advanced-stage melanoma patients. Cancer Immunol Immunother. 2006;55: 451-8.

Hakimuddin F, Paliyath G, Meckling K. Selective cytotoxicity of a red grape wine flavonoid fraction against MCF-7 cells. Breast Cancer Res Treat. 2004;85:65-79.

Hakimuddin F, Tiwari K, Paliyath G, Meckling K. Grape and wine polyphenols down-regulate the expression of signal transduction genes and inhibit the growth of estrogen receptor-negative MDA-MB231 tumors in nu/nu mouse xenografts. Nutr Res. 2008;28:702-13.

Harris DM, Besselink E, Henning SM, Go VLW, Heber D. Phytoestrogens induce differential estrogen receptor alpha- or Beta-mediated responses in transfected breast cancer cells. Exp Biol Med (Maywood). 2005;230:558-68.

Hassan ZK, et al. Oleuropein induces anti-metastatic effects in breast cancer. Asian Pacific J Cancer Prev. 2012;13:4555-9.

Helbig G, et al. NF-kappaB promotes breast cancer cell migration and metastasis by inducing the expression of the chemokine receptor CXCR4. J Biol Chem. 2003;278:21631-8.

Hibasami H, et al. Honokiol induces apoptosis in human lymphoid leukemia molt 4B cells. Int J Mol Med. 1998;2:671-4.

Hida K, Akiyama K, Ohga N, Maishi N, Hida Y. Tumour endothelial cells acquire drug resistance in a tumour microenvironment. J Biochem. 2013;153:243-9.

Hirano T, Gotoh M, Oka K. Natural flavonoids and lignans are potent cytostatic agents against human leukemic HL-60 cells. Life Sci. 1994;55:1061-9.

Hsu S, et al. Green tea polyphenol targets the mitochondria in tumor cells inducing caspase 3-dependent apoptosis. Anticancer Res. 2003;23:1533-9.

Huang MT, et al. Effect of dietary curcumin and dibenzoylmethane on formation of 7,12-dimethylbenz[a]anthracene-induced mammary tumors and lymphomas/leukemias in Sencar mice. Carcinogenesis. 1998;19:1697-700.

Huang T, Chen Z, Fang L. Curcumin inhibits LPS-induced EMT through downregulation of NF-?B-Snail signaling in breast cancer cells. Oncol Rep. 2013;29:117-24.

Huang $Y$, et al. CD4+ and CD8+ T cells have opposing roles in breast cancer progression and outcome. Oncotarget. 2015;6:17462-78.

Huang YT, et al. Effects of luteolin and quercetin, inhibitors of tyrosine kinase, on cell growth and metastasis-associated properties in A431 cells overexpressing epidermal growth factor receptor. Br J Pharmacol. 1999;128:999-1010.

Inoue $\mathrm{M}$, et al. Regular consumption of green tea and the risk of breast cancer recurrence: follow-up study from the hospital-based epidemiologic research program at Aichi Cancer center (HERPACC), Japan. Cancer Lett. 2001;167:175-82.

Isemura M, Suzuki Y, Satoh K, Narumi K, Motomiya M. Effects of catechins on the mouse lung carcinoma cell adhesion to the endothelial cells. Cell Biol Int. 1993;17:559-64.

Ishitsuka K, et al. Honokiol overcomes conventional drug resistance in human multiple myeloma by induction of caspase-dependent and -independent apoptosis. Blood. 2005;106:1794-800.

Jang J-Y, Lee J-K, Jeon Y-K, Kim C-W. Exosome derived from epigallocatechin gallate treated breast cancer cells suppresses tumor growth by inhibiting tumor-associated macrophage infiltration and M2 polarization. BMC Cancer. 2013;13(421)

Jang $M$, et al. Cancer chemopreventive activity of resveratrol, a natural product derived from grapes. Science. 1997;275:218-20. 
Jin G, et al. Combination curcumin and (-)-epigallocatechin-3-gallate inhibits colorectal carcinoma microenvironment-induced angiogenesis by JAK STAT3/IL-8 pathway. Oncogenesis. 2017;6:e384.

Jin $\mathrm{R}$, et al. NF-KB gene signature predicts prostate cancer progression. Cancer Res. 2014;74:2763-72

Jobin C, et al. Curcumin blocks cytokine-mediated NF-kappa B activation and proinflammatory gene expression by inhibiting inhibitory factor I-kappa B kinase activity. J Immunol. 1999;163:3474-83.

Johnson JJ, Mukhtar H. Curcumin for chemoprevention of colon cancer. Cancer Lett. 2007;255:170-81.

Kalinski T, et al. Curcumin blocks interleukin-1 signaling in chondrosarcoma cells. PLoS One. 2014;9:e99296.

Kalluri R, Weinberg RA. The basics of epithelial-mesenchymal transition. J Clin Invest. 2009;119:1420-8.

Kanadaswami C, et al. The antitumor activities of flavonoids. In Vivo (Brooklyn). 2005;19:895-910.

Kanayama H. Matrix metalloproteinases and bladder cancer. J Med Investig. 2001; 48:31-43.

Katiyar SK, Mukhtar H. Tea in chemoprevention of cancer: epidemiologic and experimental studies (review). Int J Oncol. 1996;8:221-38.

Kaur M, Agarwal C, Agarwal R. Anticancer and cancer chemopreventive potential of grape seed extract and other grape-based products. J Nutr. 2009;139:1806S-12S.

Kaur M, et al. Grape seed extract upregulates p21 (Cip1) through redox-mediated activation of ERK1/2 and posttranscriptional regulation leading to cell cycle arrest in colon carcinoma HT29 cells. Mol Carcinog. 2011;50:553-62.

Kawamori $\mathrm{T}$, et al. Chemopreventive effect of curcumin, a naturally occurring anti-inflammatory agent, during the promotion/progression stages of colon cancer. Cancer Res. 1999;59:597-601.

Khan S, Shukla S, Sinha S, Meeran SM. Role of adipokines and cytokines in obesity-associated breast cancer: therapeutic targets. Cytokine Growth Factor Rev. 2013;24:503-13.

Killian $\mathrm{PH}$, et al. Curcumin inhibits prostate cancer metastasis in vivo by targeting the inflammatory cytokines CXCL1 and -2 . Carcinogenesis. 2012:33:2507-19.

Kim GD, Bae SY, Park H-J, Bae K, Lee SK. Honokiol inhibits vascular vessel formation of mouse embryonic stem cell-derived endothelial cells via the suppression of PECAM and MAPK/mTOR signaling pathway. Cell Physiol Biochem. 2012:30:758-70

Kim JM, et al. Curcumin suppresses the TPA-induced invasion through inhibition of PKC??-dependent MMP-expression in MCF-7 human breast cancer cells. Phytomedicine. 2012;19:1085-92.

Kim ND, et al. Chemopreventive and adjuvant therapeutic potential of pomegranate (Punica granatum) for human breast cancer. Breast Cancer Res Treat. 2002;71:203-17.

Kim SH, Choi KC. Anti-cancer effect and underlying mechanism(s) of Kaempferol, a phytoestrogen, on the regulation of apoptosis in diverse Cancer cell models. Toxicol Res. 2013;29:229-34

Kim Y-A, et al. Resveratrol inhibits cell proliferation and induces apoptosis of human breast carcinoma MCF-7 cells. Oncol Rep. 2004;11:441-6.

Ko YS, et al. Polyphenol mixtures of Euphorbia supina the inhibit invasion and metastasis of highly metastatic breast cancer MDA-MB-231 cells. Oncol Rep. 2015;34:3035-42

Konoshima T, et al. Studies on inhibitors of skin tumor promotion, IX. Neolignans from Magnolia officinalis. J Nat Prod. 1991;54:816-22.

Kronski $E_{\text {, et }}$ al. miR181b is induced by the chemopreventive polyphenol curcumin and inhibits breast cancer metastasis via down-regulation of the inflammatory cytokines CXCL1 and -2. Mol Oncol. 2014;8:581-95.

Kumar DRN, George VC, Suresh PK, Kumar RA. Cancer-specific chemoprevention and anti-metastatic potentials of Rheum emodi rhizome ethyl acetate extracts and identification of active principles through HPLC and GC-MS analysis. Pak J Pharm Sci. 2015;28:83-93.

Kumazoe M, et al. 67-kDa laminin receptor increases cGMP to induce cancerselective apoptosis. J Clin Invest. 2013;123:787-99.

Kunnumakkara AB, Anand P, Aggarwal BB. Curcumin inhibits proliferation, invasion, angiogenesis and metastasis of different cancers through interaction with multiple cell signaling proteins. Cancer Lett. 2008;269:199-225.

Kuo ML, Huang TS, Lin JK. Curcumin, an antioxidant and anti-tumor promoter, induces apoptosis in human leukemia cells. Biochim Biophys Acta - Mol Basis Dis. 1996;1317:95-100

Lagneau $P$, et al. Is transcranial Doppler a worthwhile examination for preoperative evaluation of the circle of Willis? Evaluation of 137 carotid endarterectomies performed under regional anesthesia. Int Angiol. 1998; 17:168-70.

Laoui $D$, et al. Tumor-associated macrophages in breast cancer: distinct subsets, distinct functions. Int J Dev Biol. 2011:55:861-7.

Lee J, et al. Anti-inflammatory effects of magnolol and honokiol are mediated through inhibition of the downstream pathway of MEKK-1 in NF-kappaB activation signaling. Planta Med. 2005;71:338-43.

Lee L-T, et al. Blockade of the epidermal growth factor receptor tyrosine kinase activity by quercetin and luteolin leads to growth inhibition and apoptosis of pancreatic tumor cells. Anticancer Res. 2002;22:1615-27.

Lee SH, Jaganath IB, Wang SM, Sekaran SD. Antimetastatic effects of Phyllanthus on human lung (A549) and breast (MCF-7) cancer cell lines. PLoS One. 2011; 6:e20994.

Lee S-O, Jeong Y-J, Kim M, Kim C-H, Lee I-S. Suppression of PMA-induced tumor cell invasion by capillarisin via the inhibition of NF-kappaB-dependent MMP9 expression. Biochem Biophys Res Commun. 2008;366:1019-24.

Lee YJ, et al. Therapeutic applications of compounds in the Magnolia family. Pharmacol Ther. 2011;130:157-76.

Lewandowska $U$, et al. Procyanidins from evening primrose (Oenothera paradoxa ) defatted seeds inhibit invasiveness of breast Cancer cells and modulate the expression of selected genes involved in angiogenesis, metastasis, and apoptosis. Nutr Cancer. 2013a;65:1219-31.

Lewandowska, U. et al. Flavanols from evening primrose (Oenothera paradoxa) defatted seeds inhibit prostate cells invasiveness and cause changes in Bcl-2/ Bax mRNA ratio. Flavanols from evening primrose (Oenothera Parad. defatted seeds Inhib. prostate cells invasiveness cause Chang. $\mathrm{Bcl}-2 / \mathrm{Bax}$ mRNA ratio. 61, 2987-2998 (2013b)

Lewandowska U, et al. Flavanols from Japanese quince ( Chaenomeles Japonica ) fruit inhibit human prostate and breast Cancer cell line invasiveness and cause favorable changes in Bax/Bcl-2 mRNA ratio. Nutr Cancer. 2013c;65:273-85.

Li C, et al. Inhibitory effects of kaempferol on the invasion of human breast carcinoma cells by downregulating the expression and activity of matrix metalloproteinase-9. Biochem Cell Biol. 2015;93:16-27.

Li Y, Kong D, Wang Z, Sarkar FH. Regulation of microRNAs by natural agents: an emerging field in chemoprevention and chemotherapy research. Pharm Res. 2010;27:1027-41.

Li Z, et al. Honokiol, a natural therapeutic candidate, induces apoptosis and inhibits angiogenesis of ovarian tumor cells. Eur J Obstet Gynecol Reprod Biol. 2008;140:95-102.

Liang YC, Lin-shiau SY, Chen CF, Lin JK. Suppression of extracellular signals and cell proliferation through EGF receptor binding by (-)-epigallocatechin gallate in human A431 epidermoid carcinoma cells. J Cell Biochem. 1997;67:55-65.

Limtrakul P, Lipigorngoson S, Namwong O, Apisariyakul A, Dunn FW. Inhibitory effect of dietary curcumin on skin carcinogenesis in mice. Cancer Lett. 1997; 116:197-203.

Lin C-W, et al. Kaempferol reduces matrix metalloproteinase-2 expression by down-regulating ERK1/2 and the activator protein-1 signaling pathways in oral cancer cells. PLoS One. 2013;8:e80883.

Lin JK, Chen PC, Ho CT, Lin-Shiau SY. Inhibition of xanthine oxidase and suppression of intracellular reactive oxygen species in HL-60 cells by theaflavin-3,3'-digallate, (-)-epigallocatechin-3-gallate, and propyl gallate. J Agric Food Chem. 2000;48:2736-43.

Lin J-W, et al. Honokiol traverses the blood-brain barrier and induces apoptosis of neuroblastoma cells via an intrinsic bax-mitochondrion-cytochrome ccaspase protease pathway. Neuro-Oncology. 2012;14:302-14.

Lowery AJ, et al. MicroRNA signatures predict oestrogen receptor, progesterone receptor and HER2/neu receptor status in breast cancer. Breast Cancer Res. 2009;11:R27.

Lu J, Zhang K, Chen S, Wen W. Grape seed extract inhibits VEGF expression via reducing HIF-1alpha protein expression. Carcinogenesis. 2009;30:636-44.

Lu Y, et al. Curcumin micelles remodel tumor microenvironment and enhance vaccine activity in an advanced melanoma model. Mol Ther. 2016;24:364-74.

Luo H, Daddysman MK, Rankin GO, Jiang B-H, Chen YC. Kaempferol enhances cisplatin's effect on ovarian cancer cells through promoting apoptosis caused by down regulation of cMyc. Cancer Cell Int. 2010;10:16.

Luo $\mathrm{H}$, Jiang B-H, King SM, Chen YC. Inhibition of cell growth and VEGF expression in ovarian cancer cells by flavonoids. Nutr Cancer. 2008:60:800-9.

Luo KW, et al. Green tea (Camellia sinensis) extract inhibits both the metastasis and osteolytic components of mammary cancer $4 \mathrm{TT} 1$ lesions in mice. J Nutr Biochem. 2014;25:395-403. 
MacDougall JR, Matrisian LM. Contributions of tumor and stromal matrix metalloproteinases to tumor progression, invasion and metastasis. Cancer and Metastasis Rev. 1995;14:351-62.

Mahmoud SMA, et al. Tumor-infiltrating CD8+ lymphocytes predict clinical outcome in breast cancer. J Clin Oncol. 2011;29:1949-55.

Makris DP, Boskou G, Andrikopoulos NK. Recovery of antioxidant phenolics from white vinification solid by-products employing water/ethanol mixtures. Bioresour Technol. 2007;98:2963-7.

Masuda M, et al. Epigallocatechin-3-gallate decreases VEGF production in head and neck and breast carcinoma cells by inhibiting EGFR-related pathways of signal transduction. J Exp Ther Oncol. 2002;2:350-9.

Matrisian LM. Metalloproteinases and their inhibitors in matrix remodeling. Trends Genet. 1990;6:121-5.

McCawley LJ, Matrisian LM. Matrix metalloproteinases: multifunctional contributors to tumor progression. Mol Med Today. 2000;6:149-56.

McLarty J, et al. Tea polyphenols decrease serum levels of prostate-specific antigen, hepatocyte growth factor, and vascular endothelial growth factor in prostate cancer patients and inhibit production of hepatocyte growth factor and vascular endothelial growth factor in v. Cancer Prev. Res (Phila). 2009;2:673-82.

Mehlen P, Puisieux A. Metastasis: a question of life or death. Nat Rev Cancer. 2006:6:449-58.

Mehta K, Pantazis P, McQueen T, Aggarwal BB. Antiproliferative effect of curcumin (diferuloylmethane) against human breast tumor cell lines. AntiCancer Drugs. 1997;8:470-81.

Miller TE, et al. MicroRNA-221/222 confers tamoxifen resistance in breast cancer by targeting p27Kip1. J Biol Chem. 2008;283:29897-903.

Moghaddam SJ, et al. Curcumin inhibits COPD-like airway inflammation and lung cancer progression in mice. Carcinogenesis. 2009;30:1949-56.

Morré DM, Morré DJ. Anticancer activity of grape and grape skin extracts alone and combined with green tea infusions. Cancer Lett. 2006;238:202-9.

Nagalingam A, Arbiser JL, Bonner MY, Saxena NK, Sharma D. Honokiol activates AMP-activated protein kinase in breast cancer cells via an LKB1-dependent pathway and inhibits breast carcinogenesis. Breast Cancer Res. 2012;14:R35.

Nagase H, Ikeda K, Sakai Y. Inhibitory effect of magnolol and honokiol from Magnolia obovata on human fibrosarcoma HT-1080. Invasiveness in vitro. Planta Med. 2001;67:705-8.

Nakachi K, et al. Influence of drinking green tea on breast cancer malignancy among Japanese patients. Jpn J Cancer Res. 1998;89:254-61.

Nakagawa $\mathrm{H}$, et al. Resveratrol inhibits human breast cancer cell growth and may mitigate the effect of linoleic acid, a potent breast cancer cell stimulator. J Cancer Res Clin Oncol. 2001;127:258-64.

Naveen Kumar DR, Cijo George V, Suresh PK, Ashok Kumar R. Acceleration of procaspase-3 maturation and cell migration inhibition in human breast cancer cells by phytoconstituents of Rheum emodi rhizome extracts. EXCLI J. 2013; 12:462-78.

NCI SEER data analysis 2000-2005 2018.

Negro C, Tommasi L, Miceli A. Phenolic compounds and antioxidant activity from red grape marc extracts. Bioresour Technol. 2003;87:41-4.

Nieman KM, Romero IL, Van Houten B, Lengyel E. Adipose tissue and adipocytes support tumorigenesis and metastasis. Biochim Biophys Acta. 2013;1831: 1533-41.

Nifli A-P, Kampa M, Alexaki V-I, Notas G, Castanas E. Polyphenol interaction with the T47D human breast cancer cell line. J Dairy Res. 2005;72:44.

Noratto G, Porter W, Byrne D, Cisneros-Zevallos L. Polyphenolics from peach (Prunus persica var. rich lady) inhibit tumor growth and metastasis of MDAMB-435 breast cancer cells in vivo. J Nutr Biochem. 2014;25:796-800.

O'Shaughnessy J. Extending survival with chemotherapy in metastatic breast cancer. Oncologist. 2005;10(Suppl 3):20-9.

Oh SM, Kim YP, Chung KH. Biphasic effects of kaempferol on the estrogenicity in human breast cancer cells. Arch Pharm Res. 2006;29:354-62.

Ohashi Y, Tsuchiya Y, Koizumi K, Sakurai H, Saiki I. Prevention of intrahepatic metastasis by curcumin in an orthotopic implantation model. Oncology. 2003;65:250-8

Paget S. The distribution of secondary growths in cancer of the breast. 1889 . Cancer Metastasis Rev. 1989;8:98-101.

Pagliacci MC, et al. Growth-inhibitory effects of the natural phyto-oestrogen genistein in MCF-7 human breast cancer cells. Eur J Cancer. 1994;30A: 1675-82.

Park E-J, et al. Down-regulation of c-Src/EGFR-mediated signaling activation is involved in the honokiol-induced cell cycle arrest and apoptosis in MDA-MB231 human breast cancer cells. Cancer Lett. 2009;277:133-40.
Peinado H, Olmeda D, Cano A. Snail, Zeb and bHLH factors in tumour progression: an alliance against the epithelial phenotype? Nat Rev Cancer. 2007;7:415-28.

Pelicano H, Carney D, Huang P. ROS stress in cancer cells and therapeutic implications. Drug Resist Updat. 2004;7:97-110.

Peterson G, Barnes S. Genistein inhibition of the growth of human breast cancer cells: independence from estrogen receptors and the multi-drug resistance gene. Biochem Biophys Res Commun. 1991;179:661-7.

Pianetti S, Guo S, Kavanagh KT, Sonenshein GE. Green tea polyphenol epigallocatechin-3 gallate inhibits her-2/neu signaling, proliferation, and transformed phenotype of breast cancer cells. Cancer Res. 2002;62:652-5.

Plummer SM, et al. Inhibition of cyclo-oxygenase 2 expression in colon cells by the chemopreventive agent curcumin involves inhibition of NF-kappaB activation via the NIK/KK signalling complex. Oncogene. 1999;18:6013-20.

Provinciali $\mathrm{M}$, et al. Effect of resveratrol on the development of spontaneous mammary tumors in HER-2/neu transgenic mice. Int J Cancer. 2005;115:36-45.

Quail DF, Joyce JA. Microenvironmental regulation of tumor progression and metastasis. Nat Med. 2013;19:1423-37.

Rajendran $\mathrm{P}$, et al. Honokiol inhibits signal transducer and activator of transcription-3 signaling, proliferation, and survival of hepatocellular carcinoma cells via the protein tyrosine phosphatase SHP-1. J Cell Physiol. 2012;227:2184-95.

Ramachandran C, You W. Differential sensitivity of human mammary epithelial and breast carcinoma cell lines to curcumin. Breast Cancer Res Treat. 1999:54:269-78.

Ramsay DT, Kent JC, Hartmann RA, Hartmann PE. Anatomy of the lactating human breast redefined with ultrasound imaging. J Anat. 2005;206:525-34.

Reeves GK, et al. Cancer incidence and mortality in relation to body mass index in the million women study: cohort study. BMJ. 2007;335:1134.

Reuter S, Gupta SC, Park B, Goel A, Aggarwal BB. Epigenetic changes induced by curcumin and other natural compounds. Genes Nutr. 2011;6:93-108.

Rhee J-S, Coussens LM. RECKing MMP function: implications for cancer development. Trends Cell Biol. 2002;12:209-11.

Saini S, et al. Curcumin modulates microRNA-203-mediated regulation of the Src-Akt axis in bladder cancer. Cancer Prev Res (Phila). 2011;4:1698-709.

Saito $\mathrm{N}$, et al. A double three-step theory of brain metastasis in mice: the role of the pia mater and matrix metalloproteinases. Neuropathol Appl Neurobiol. 2007;33:288-98.

Sartippour MR, et al. Green tea and its catechins inhibit breast cancer xenografts. Nutr Cancer. 2001;40:149-56.

Schlachterman A, et al. Combined resveratrol, quercetin, and catechin treatment reduces breast tumor growth in a nude mouse model. Transl Oncol. 2008;1:19-27.

Sen T, Chatterjee A. Epigallocatechin-3-gallate (EGCG) downregulates EGF-induced MMP-9 in breast cancer cells: involvement of integrin receptor a5 $\beta 1$ in the process. Eur J Nutr. 2011;50:465-78.

Sen T, Dutta A, Chatterjee A. Epigallocatechin-3-gallate (EGCG) downregulates gelatinase-B (MMP-9) by involvement of FAK/ERK/NFkappaB and AP-1 in the human breast cancer cell line MDA-MB-231. Anti-Cancer Drugs. 2010;21:632-44.

Sen T, et al. Multifunctional effect of epigallocatechin-3-gallate (EGCG) in downregulation of gelatinase-a (MMP-2) in human breast cancer cell line MCF-7. Life Sci. 2009;84:194-204.

Shammas $\mathrm{M}$ a, et al. Specific killing of multiple myeloma cells by (-)-epigallocatechin-3-gallate extracted from green tea: biologic activity and therapeutic implications. Blood. 2006;108:2804-10.

Shao Z-M, et al. Curcumin exerts multiple suppressive effects on human breast carcinoma cells. Int J Cancer. 2002;98:234-40.

Sheu ML, et al. Inhibition of NADPH oxidase-related oxidative stress-triggered signaling by honokiol suppresses high glucose-induced human endothelial cell apoptosis. Free Radic Biol Med. 2008;44:2043-50.

Shiga K, et al. Cancer-associated fibroblasts: their characteristics and their roles in tumor growth. Cancers (Basel). 2015;7:2443-58.

Shigemura K, et al. Honokiol, a natural plant product, inhibits the bone metastatic growth of human prostate cancer cells. Cancer. 2007;109:1279-89.

Shishodia S, Potdar P, Gairola CG, Aggarwal BB. Curcumin (diferuloylmethane) down-regulates cigarette smoke-induced NF-kappaB activation through inhibition of IkappaBalpha kinase in human lung epithelial cells: correlation with suppression of COX-2, MMP-9 and cyclin D1. Carcinogenesis. 2003;24:1269-79.

Singh RP, Tyagi AK, Dhanalakshmi S, Agarwal R, Agarwal C. Grape seed extract inhibits advanced human prostate tumor growth and angiogenesis and upregulates insulin-like growth factor binding protein-3. Int J Cancer. 2004; 108:733-40. 
Singh T, Katiyar SK. Honokiol inhibits non-small cell lung cancer cell migration by targeting $\mathrm{PGE}_{2}$-mediated activation of $\beta$-catenin signaling. PLOS One. 2013;8: e60749.

Singletary KW, et al. Inhibition of rat mammary tumorigenesis by concord grape juice constituents. J Agric Food Chem. 2003;51:7280-6.

Sliva D, Rizzo MT, English D. Phosphatidylinositol 3-kinase and NF-kappaB regulate motility of invasive MDA-MB-231 human breast cancer cells by the secretion of urokinase-type plasminogen activator. J Biol Chem. 2002;277:3150-7.

Slivova $V$, et al. Green tea polyphenols modulate secretion of urokinase plasminogen activator (UPA) and inhibit invasive behavior of breast cancer cells. Nutr Cancer. 2005;52:66-73.

Soleas GJ, Grass L, Josephy PD, Goldberg DM, Diamandis EP. A comparison of the anticarcinogenic properties of four red wine polyphenols. Clin Biochem. 2002;35:119-24.

Srinivas, N. R. Recent trends in preclinical drug - drug interaction studies of flavonoids - review of case studies, issues and Perspectives. 2015;1691, 1679-1691.

Su CM, et al. Trichodermin induces cell apoptosis through mitochondrial dysfunction and endoplasmic reticulum stress in human chondrosarcoma cells. Toxicol Appl Pharmacol. 2013;272:335-44.

Subbaramaiah K, et al. Resveratrol inhibits cyclooxygenase-2 transcription in human mammary epithelial cells. Ann N Y Acad Sci. 1999;889:214-23.

Sun T, Chen QY, Wu LJ, Yao XM, Sun XJ. Antitumor and antimetastatic activities of grape skin polyphenols in a murine model of breast cancer. Food Chem Toxicol. 2012;50:3462-7.

Sung B, et al. Curcumin circumvents chemoresistance in vitro and potentiates the effect of thalidomide and bortezomib against human multiple myeloma in nude mice model. Mol Cancer Ther. 2009;8:959-70.

Syng-Ai C, Kumari AL, Khar A. Effect of curcumin on normal and tumor cells: role of glutathione and bcl-2. Mol Cancer Ther. 2004;3:1101-8.

Tachibana H, Koga K, Fujimura Y, Yamada K. A receptor for green tea polyphenol EGCG. Nat Struct Mol Biol. 2004;11:380-1.

Tessitore L, Davit A, Sarotto I, Caderni G. Resveratrol depresses the growth of colorectal aberrant crypt foci by affecting bax and p21(CIP) expression. Carcinogenesis. 2000;21:1619-22.

Torres $J$, et al. Valorization of grape (Vitis vinifera) byproducts. Antioxidant and biological properties of polyphenolic fractions differing in procyanidin composition and flavonol content. J Agric Food Chem. 2002;50:7548-55.

Tsai SH, Lin-Shiau SY, Lin JK. Suppression of nitric oxide synthase and the downregulation of the activation of NFkappaB in macrophages by resveratrol. $\mathrm{Br}$ J Pharmacol. 1999;126:673-80

Tse AK-W, Wan C-K, Shen X-L, Yang M, Fong W-F. Honokiol inhibits TNF-alphastimulated NF-kappaB activation and NF-kappaB-regulated gene expression through suppression of IKK activation. Biochem Pharmacol. 2005;70:1443-57.

Umeda D, Yano S, Yamada K, Tachibana H. Green tea polyphenol epigallocatechin-3-gallate signaling pathway through 67-kDa laminin receptor. J Biol Chem. 2008:283:3050-8.

Van Aller GS, et al. Epigallocatechin gallate (EGCG), a major component of green tea, is a dual phosphoinositide-3-kinase/mTOR inhibitor. Biochem Biophys Res Commun. 2011;406:194-9.

Van den Steen PE, et al. Biochemistry and molecular biology of gelatinase B or matrix metalloproteinase-9 (MMP-9). Crit Rev Biochem Mol Biol. 2002;37:375-536.

Vandeweyer, E. \& Hertens, D. Quantification of glands and fat in breast tissue: an experimental determination. Ann Anat. 2002;184, 181-184.

Verma RP, Hansch C. Matrix metalloproteinases (MMPs): chemical-biological functions and (Q)SARs. Bioorg Med Chem. 2007;15:2223-68.

Visse R, Nagase H. Matrix metalloproteinases and tissue inhibitors of metalloproteinases: structure, function, and biochemistry. Circ Res. 2003;92:827-39.

Wang T, et al. Honokiol induces apoptosis through p53-independent pathway in human colorectal cell line RKO. World J Gastroenterol. 2004;10:2205-8.

Wang $X$, et al. Honokiol crosses BBB and BCSFB, and inhibits brain tumor growth in rat $9 \mathrm{~L}$ intracerebral gliosarcoma model and human U251 xenograft glioma model. PLoS One. 2011;6:e18490.

Watanabe $\mathrm{H}$, et al. Purification of human tumor cell autocrine motility factor and molecular cloning of its receptor. J Biol Chem. 1991;266:13442-8.

Wen J, et al. Anti-psoriatic effects of Honokiol through the inhibition of NF-kB and VEGFR-2 in animal model of K14-VEGF transgenic mouse. J Pharmacol Sci. 2015;128:116-24.

Wilken R, Veena MS, Wang MB, Srivatsan ES. Curcumin: a review of anti-cancer properties and therapeutic activity in head and neck squamous cell carcinoma. Mol Cancer. 2011;10:12
Woodbury A, Yu SP, Wei L, García P. Neuro-modulating effects of honokiol: a review. Front Neurol. 2013:4:130.

Wu JT, Kral JG. The NF-kappaB/lkappaB signaling system: a molecular target in breast cancer therapy. J Surg Res. 2005:123:158-69.

Xia EQ, Deng GF, Guo YJ, Li HB. Biological activities of polyphenols from grapes. Int J Mol Sci. 2010;11:622-46.

Xu Y, et al. Resveratrol protects against hyperglycemia-induced oxidative damage to mitochondria by activating SIRT1 in rat mesangial cells. Toxicol Appl Pharmacol. 2012;259:395-401.

Yang CS, Maliakal P, Meng X. Inhibition of carcinogenesis by tea. Annu Rev Pharmacol Toxicol. 2002:42:25-54.

Yang CS, Wang X, Lu G, Picinich SC. Cancer prevention by tea: animal studies, molecular mechanisms and human relevance. Nat Rev Cancer. 2009;9:429-39

Yang CS, Wang ZY. Tea and Cancer. J Natl Cancer Inst. 1993;85:1038-49.

Yang EB, Zhang K, Cheng LY, Mack P. Butein, a specific protein tyrosine kinase inhibitor. Biochem Biophys Res Commun. 1998;245:435-8.

Yang J, Wei D, Liu J. Repressions of MMP-9 expression and NF-kappaB localization are involved in inhibition of lung carcinoma 95-D cell invasion by (-)-epigallocatechin-3- gallate. Biomed Pharmacother. 2005;59:98-103.

Yang J, Weinberg RA. Epithelial-mesenchymal transition: at the crossroads of development and tumor metastasis. Dev Cell. 2008;14:818-29.

Yang SE, Hsieh MT, Tsai TH, Hsu SL. Down-modulation of BCl-XL, release of cytochrome $\mathrm{c}$ and sequential activation of caspases during honokiol-induced apoptosis in human squamous lung cancer $\mathrm{CH} 27$ cells. Biochem Pharmacol. 2002;63:1641-51.

Ye J, Gao Z, Yin J, He Q. Hypoxia is a potential risk factor for chronic inflammation and adiponectin reduction in adipose tissue of $\mathrm{Ob} / \mathrm{Ob}$ and dietary obese mice. Am J Physiol Endocrinol Metab. 2007;293:E1118-28.

Yeh P-S, et al. Honokiol induces autophagy of neuroblastoma cells through activating the PI3K/Akt/mTOR and endoplasmic reticular stress/ERK1/2 signaling pathways and suppressing cell migration. Cancer Lett. 2016;370:66-77.

Yu T, Di G. Role of tumor microenvironment in triple-negative breast cancer and its prognostic significance. Chin J Cancer Res. 2017;29:237-52.

Zhang Y, et al. Downregulation of STAT3 and activation of MAPK are involved in the induction of apoptosis by HNK in glioblastoma cell line U87. Oncol Rep. 2014;32:2038-46

Zhu W, et al. 5-Formylhonokiol exerts anti-angiogenesis activity via inactivating the ERK signaling pathway. Exp Mol Med. 2011;43:146-52.

Zhu X, Wang Z, Hu C, Li Z, Hu J. Honokiol suppresses TNF-a-induced migration and matrix metalloproteinase expression by blocking NF-KB activation via the ERK signaling pathway in rat aortic smooth muscle cells. Acta Histochem. 2014;116:588-95

\section{Ready to submit your research? Choose BMC and benefit from:}

- fast, convenient online submission

- thorough peer review by experienced researchers in your field

- rapid publication on acceptance

- support for research data, including large and complex data types

- gold Open Access which fosters wider collaboration and increased citations

- maximum visibility for your research: over $100 \mathrm{M}$ website views per year

At BMC, research is always in progress.

Learn more biomedcentral.com/submissions 